\title{
A Comprehensive Evaluation of Surface Air Temperature Reanalyses over China against Urbanization Bias-Adjusted Observations
}

\section{Siqi Zhang ( $\sim$ 444902334@qq.com )}

National Climate Center

\section{Guoyu Ren}

China University of Geosciences (CUG) https://orcid.org/0000-0002-9351-4179

\section{Yuyu Ren}

National Climate Center, China Meteorological Administration (CMA)

\section{Yingxian Zhang}

National Climate Center, China Meteorological Administration (CMA)

\section{Xiaoying Xue}

China University of Geosciences (CUG),

\section{Original Paper}

Keywords: temperature, reanalysis data, urbanization bias, adjusted observations, comparison, evaluation, China

Posted Date: February 12th, 2021

DOl: https://doi.org/10.21203/rs.3.rs-182529/v1

License: (c) (1) This work is licensed under a Creative Commons Attribution 4.0 International License. Read Full License 
A Comprehensive Evaluation of Surface Air Temperature Reanalyses over China against Urbanization-bias-adjusted Observations 5 Siqi Zhang ${ }^{1.2 .3}$ Guoyu Ren ${ }^{1.2}$ Yuyu Ren ${ }^{2} \quad$ Yingxian Zhang $^{2} \quad$ Xiaoying Xue ${ }^{1}$

1. Department of Atmospheric Science, School of Environmental Studies, China University of Geosciences (CUG), Wuhan 430074, China

2. Laboratory for Climate Studies, National Climate Center, China Meteorological Administration (CMA), China

3 Key laboratory for Cloud Physics of China Meteorological Administration, Beijing 100081, China

*Corresponding author: Guoyu Ren

(Email: guoyoo@cma.gov.cn; Tel: +86 010-68406408)

Submitted to Theoretical and Applied Climatology for possible publication 


\section{ABSTRACT}

The goal of this study is to compare the differences in surface air temperature (SAT) between observational and reanalysis data in mainland China from 1961-2015 for evaluating the reliability and applicability of the reanalysis datasets, based on an observational dataset of 763 stations which has been adjusted for urbanization bias, and 8 reanalysis datasets. The time series, anomaly correlations, standard deviations, climate state, and linear trends of the reanalysis data are evaluated against the observations. The reanalysis data are consistent with the observational climate characteristics to a large extent. The correlation and standard deviation ratio between the reanalysis data and observations exhibited highly consistent inter-annual variability and dispersion, with the inter-annual SAT variability of JRA55 and ERA5 the closest to the observations for the periods 1961-2015 and 1979-2015, and the dispersions of 20CRV3 and NCEPV1 the most consistent with the observations for the two periods. The annual mean SAT of the reanalyses is generally $0-2.0^{\circ} \mathrm{C}$ lower than the observations, while the linear trends of all datasets exhibited clear warming. The biases in the SAT climatology of 20CRV3 and CRA40 are lower than other reanalysis datasets, and the linear trends of NCEPV1 and 20CRV3 are closer to the observations. With increasing elevation, the biases of the reanalysis data in terms of correlation, standard deviation, climate state, and linear trend all increased. Overall, in terms of the similarity of multiple measures to the urbanization biasadjusted observations, CRA40 and JRA55 show the best performance of the products in reproducing various aspects of climatological and climate change features in mainland China for the period 1979-2015 and 1961-2015 respectively.

KEY WORDS: temperature; reanalysis data; urbanization bias; adjusted observations; comparison; evaluation; China

\section{INTRODUCTION}

Reanalysis datasets have been widely used in climate change and climatological research. Over the past 30 years, the United States, the European Union, and Japan have produced a series of reanalysis datasets. The fourth generation reanalysis datasets have now been developed, which include NCEP-NCAR (Kalnay et al., 1996), NCEP-DOE (Kanamitsu et al., 2002), CFSR (Saha et al., 2010), NASA-MERRA (Rienecker et al., 2011), 20CR (Compo et al., 2011), ERA-interim (Dee et al., 2011), and JRA55 (Kobayashi et al., 2015).

The ERA5 and CRA40 were developed by the European Centre for Medium-Range Weather Forecasts (ECMWF) (Hersbach et al., 2020) and China Meteorological Administration (CMA) (Liang et al., 2020), respectively, as the new datasets in 2019. In addition, the NOAA-CIRESDOE Twentieth Century Reanalysis (20CR) project has generated an updated four-dimensional global atmospheric dataset spanning the period 1836-2015 to replace the current 20CRV2 and 20CRV2C datasets. Since these reanalyses have the disadvantages of incorporating the errors from the numerical prediction models, the assimilation processes, and the observation systems (Bengtsson et al., 2004a, 2004b; Zhao et al., 2010; Zhao et al., 2015), the reliability of the reanalysis data needs to be proven on global and regional scales.

Kistler et al. (2001) showed that the surface air temperatures belonging to class B were generally not as reliable as air pressure. Liu et al. (2008) compared NCEPV2 and ERA-40 to buoy observations and found that the reanalysis had warm biases and underestimated the observed interannual variability of summer surface air temperature from 1979-1999. Lindsay et al. (2014) showed that the third generation models (CFSR, MERRA, and ERA-Interim) stood out as being 
more consistent with independent observations for period 1981-2010 in the Arctic region. Fan and Liu (2013) indicated the consistency of SAT climatology in the Southern Hemisphere for the data derived from 20CR and observations from 1979-2010. Zhou et al. (2016) evaluated the SATs in reanalysis data (NCEPV1, NCEPV2, JRA55, ERA-interim, and MERRA) over global deserts, revealing annual mean values ranging from $20.8-24.5^{\circ} \mathrm{C}$ and long-term trends varying from 0.10 $0.14^{\circ} \mathrm{C} /$ decade.

With the newly-developed reanalysis datasets, many researchers have examined the reliability and applicability of reanalysis surface air temperatures in China ( $\mathrm{Su}$ et al., 1999; Xu et al., 2001; Zhao et al., 2006; Gao et al., 2010; Li et al., 2012; He et al., 2013; Zhu et al., 2015). The biases in inter-annual variability, time series, and spatial distribution characteristics between reanalysis and observational data have been analyzed. The results revealed that the application of reanalysis air temperature in eastern China was more consistent with observation than the application in western China (Zhao et al., 2006; Zhu et al., 2015). The climate characteristics displayed by the datasets had a higher agreement with observations after 1979 than before 1979, reflecting the fact that the new generation reanalysis data were generally better than the old products.

Many researchers have confirmed the above conclusions and found that the bias of SAT between reanalysis and observation was affected by elevation (Ma et al., 2008; Zhao et al., 2006; Zhou et al., 2018). The biases in the temperature trends were derived jointly from those in atmospheric downward long-wave radiation and precipitation frequency. For the linear trend bias of temperature from 1909-2010, Zhang et al. (2019) analyzed the linear trend of temperature in eastern China based on the homogenized data of 16 observation stations and two sets of 20th century reanalysis data (20CR and ERA20C), and found that, although ERA20C was generally closer to the observational temperatures than 20CR from 1909-2010, their consistency did not indicate that ERA20C and 20CRV2 were suitable for climate change research due to the systematic bias related to the observational data from the stations.

The aforementioned studies revealed the uncertainties of reanalysis datasets in different regions and different periods. These may be due to limited assimilation sources, errors from the numerical prediction models, and observation system changes, which produced different results for different periods and regions (Xu et al., 2001; Thorne and Vose, 2010; Parker, 2016; Lahoz and Schneider, 2014; Dee et al., 2014; Zhou et al., 2017). In addition, the previous comparisons of SAT data between reanalysis and observation generally considered the inhomogeneity of the reference data, but ignored the bias of the linear trend caused by the urbanization that has occurred in recent decades. Thus, the question as to how to evaluate the potential of reanalysis data for climate change research has not been given sufficient attention, since the effects of urbanization have not been considered.

There have been many recent studies demonstrating that the SAT observation records of urban stations and national meteorological station networks contain a significant urbanization bias, regardless of whether homogenization corrections were applied, especially since the middle of the 20th century in China (Ren et al., 2007, 2008; Hua et al., 2008; Li et al., 2010; Ren and Ren, 2011; Wang and Ge, 2012; He et al., 2013; Ren and Zhou, 2014; Shi et al., 2015; Li et al., 2016). Due to the differences in research regions, time periods, and data processing methods, and, in particular, to the differences in the reference stations networks that were applied, estimating of the urbanization effect and contribution varied among the different research groups. It was therefore necessary to develop an actual rural (reference) national station network for assessing and adjusting 
the current temperature biases in the national historical SAT datasets widely used in studies of climate change. This national station network has been conducted for mainland China over the last decade by the CMA (Ren et al., 2008, 2015; Zhang et al., 2010; Ren and Zhou, 2014; Wen et al., 2019). Wen et al. (2019) recently adjusted the monthly 1961-2015 temperature data of 763 national stations in China for urbanization bias based on previous research. Their study concluded that the trend of the original temperature was $0.048-0.049^{\circ} \mathrm{C} / 10 \mathrm{year}$ higher than that of the urbanization bias adjusted temperature series. Therefore, the urbanization bias adjustment removed systematic bias in the quality-controlled and homogenized data, which had caused an overestimate of the annual warming rate of more than $19.6 \%$. In addition, the spatial patterns of the annual mean SAT linear trends also exhibit an obvious difference from those of the previous analyses. Wen et al. (2019) concluded that a weak warming area appear in the small part of southwestern North China, the northwestern Central China and the eastern part of Southwest China. The annual mean warming trends in Northeast and North China obviously decreased, which caused a relatively more significant cooling in Northeast China after 1998. This indicates that the influence of urbanizationbias on the estimate of temperature trend is not ignorable. This adjusted dataset is thus considered to be the most suitable one for use in monitoring and studying regional climate change in China than the only homogenized temperature data.

It remains necessary, therefore, to evaluate climatology and the long-term trends of the $2 \mathrm{~m}$ air temperature of the reanalysis data against the new observational data exempt from urbanization bias. In this study, we evaluate the applicability of the reanalysis data by using the urbanization bias-adjusted observational data from 1961-2015 across mainland China. The results of this work can serve as a reference for both developers of reanalysis data and researchers of climate change.

\section{MATERIALS AND METHODS}

The monthly mean surface air temperature (referred to as SAT) observational dataset (referred to as OBS) of 763 national meteorological stations across China for the period 1961-2015 was developed by adjusting for urbanization bias (Wen et al. 2019) after it had been adjusted for inhomogeneities mainly caused by station and instrumentation relocation (Cao et al., 2016). The distribution of the stations is shown in Figure 1. The method of urbanization bias-adjustment consisted of 3 steps: (1) The SAT reference station networks developed in previous studies (Ren et al., 2010; Ren et al., 2015) were applied, and the reference stations chosen for any target stations were stipulated to be within $500 \mathrm{~km}$ (Janis et al., 2004; Ren et al., 2012); (2) The weighted averages of monthly mean temperature for all reference stations were calculated using the correlation coefficients of the detrended monthly mean temperature series between the reference stations and the target station as weights; (3) The linear trend bias of temperature between the target station and the reference series was used as the total correction in order to adjust for urbanization bias at each target station (Zhang et al., 2009). Given the lack of high-quality observational data before 1961, we selected 1961-2015 as the research period for comparing the observational and reanalysis temperatures.

Figure 1. Distribution of the elevation distribution and 763 observation stations across mainland China. (The insert shows the number of stations at various elevations, the asl stands for elevation (units: $\mathrm{m}$ ), the red bar stands for the number of the elevation distribution) 
The reanalysis data used in this study include fourth-generation datasets (Table 1), referred to as REAs. The first-generation NCEPV1 dataset, which was produced by NCEP/NCAR, was assimilated with weather observations from ships, weather stations, satellites, and other sources. The second-generation NCEPV2 was an improvement over the NCEPV1. CFSR, MERRA, and JRA55 were the third-generation which had much higher spatial and temporal resolution than the NCEPV1 and NCEPV2. The new generation ERA5, CRA40, and 20CRV3 datasets have now been released. Compared with the ERA-interim, the ERA5 has better global distribution of precipitation and more consistent observations of sea surface temperature and sea ice. Based on the NCEP's global spectral model (GSM) and lattice statistical interpolation (GSI) assimilation system, the CMA produced the first reanalysis dataset CRA40 in 2019, which assimilated high-density domestic and overseas observational data and satellite data. The 20CRV3, which is the most recent version of 20CR reanalysis, assimilates only surface observations of synoptic pressure into NOAA's Global Forecast System and prescribes sea surface temperature and sea ice distribution. The 20CRV3 is better than the 20CRV1, 20CRV2, and 20CRV2C in assimilating more of the early data that were collected with international cooperation under the Atmospheric Circulation Reconstructions over the Earth (ACRE) project.

Table 1. Atmospheric reanalysis datasets applied in this study

Due to differences in the periods of the reanalysis data, as well as the availability of highquality observational data, we select the common period 1961-2015 as the research period, which is consistent with the urbanization bias-adjusted observations in terms of data series length. In addition to the entire period, 1979-2015 is also used for comparing the reanalysis and observational data, given the application of satellite data in assimilation, the production of more reanalysis data, and the rapid global warming since 1979 (Tang et al., 2005; Ren et al., 2012). Climate reference period is the 30 years of 1981-2010 in this study. The bilinear interpolation method is utilized to interpolate the monthly mean SATs of the reanalysis to the observational stations, using data of four reanalysis grid boxes around each station. The time series, correlation, standard deviation, climate state, and linear trends of the reanalysis data are evaluated against the observations. The annual mean SATs are calculated from the observations and reanalysis data based on 12 monthly mean values.

The correlation coefficient (R) and the standard deviation ratio (SDR) between the REAs and OBS represent the degree of similarity in the annual variability and standard deviation, respectively. A value of SDR or $\mathrm{R}$ close to 1.0 reflects a higher similarity between the observations and reanalysis data.

$$
R=\frac{\sum_{i=1}^{n}\left(R E A_{i}-\overline{R E A}\right)\left(O B S_{i}-\overline{O B S}\right)}{\sqrt{\sum_{i=1}^{n}\left(R E A_{i}-\overline{R E A}\right)^{2}} \sqrt{\sum_{i=1}^{n}\left(O B S_{i}-\overline{O B S}\right)^{2}}}
$$




$$
S D R=\frac{\sqrt{\frac{1}{n} \sum_{i=1}^{n}\left(R E A_{i}-\overline{R E A}\right)^{2}}}{\sqrt{\frac{1}{n} \sum_{i=1}^{n}\left(O B S_{i}-\overline{O B S}\right)^{2}}}
$$

The significance of climate trend (S) represents the quantitative degree of temperature rise and fall under climate change. The linear trend (a) is the regression coefficient obtained by the leastsquares method.

$$
S=\frac{\sum_{i=1}^{n}\left(R E A_{i}-\overline{R E A}\right)\left(i-\frac{n+1}{2}\right)}{\sqrt{\sum_{i=1}^{n}\left(R E A_{i}-\overline{R E A}\right)^{2}} \sqrt{\sum_{i=1}^{n}\left(i-\frac{n+1}{2}\right)^{2}}}
$$

$$
\alpha=S \frac{\sqrt{\frac{1}{n} \sum_{i=1}^{n}\left(R E A_{i}-\overline{R E A}\right)^{2}}}{\sqrt{\frac{1}{n} \sum_{i=1}^{1}\left(i-\frac{n+1}{2}\right)^{2}}}
$$

The relative biases between the REAs and OBS for correlation, standard deviation, climate state and linear trends are calculated for the periods 1961-2015 and 1979-2015. Then, the difference between $100 \%$ and absolute value of the relative bias is regarded as the score to each of the metrics (inter-annual variability, dispersion, climate state and linear trend), and is used to calculate the integrated scores in arithmetic mean for each of the reanalysis datasets. 


\section{Results}

\subsection{Temporal features}

The time series of annual mean SAT across China from the REAs and OBS (Figure 2a) reveal that the REAs describe the observational SAT characteristics in the inter-annual variation over the entire study period. The annual mean SAT of the REAs is generally $0-2.0^{\circ} \mathrm{C}$ lower than the OBS, and that of CRA40 is closer to the OBS than the other REAs. The bias between MERRA and the OBS is larger than that between CRA40 and the OBS from 2000-2010. Furthermore, a more significant bias $\left(>1.5^{\circ} \mathrm{C}\right)$ of the REAs is found for NCEPV1, NCEPV2, and CFSR, indicating that differences in the reanalysis model and assimilation scheme may affect reanalysis data quality. Figures $2 b$ and $2 c$ show the time series of annual mean SAT anomalies and their detrended series from 1961-2015 across China, respectively. The REAs well describe the SAT characteristics of the OBS in the inter-annual variability over the entire study period. CRA40, JRA55 and ERA5 are more consistent with the OBS than the other reanalysis datasets from 1979-2015. JRA55 is closer to the observations than 20CRV3 and NCEPV1 before 1979.

Figure 2. Time series of annual mean SAT across mainland China from 1961-2015 derived from OBS and REAs: (a) SAT; (b) SAT anomalies; (c) SAT with linear trends removed. (units: ${ }^{\circ} \mathrm{C}$ )

Figure 3 also shows that CRA40 is more consistent with the OBS in seasonal and inter-annual temperature variations. Partial REAs show larger cold biases generally occurring in April-October $\left(>1.0^{\circ} \mathrm{C}\right.$ in August) and CRA40 show smaller warm biases in November-February. The bias between MERRA and the OBS is larger from 2000-2010 than at other times, mainly as a result of significantly cold biases in July-December 1979-2015 and January-July 2000-2010, respectively. The monthly mean SAT derived from the REAs (NCEPV1, NCEPV2, ERA5, JRA55, 20CRV3, and CFSR) exhibit cold systematic biases, with the biases of NCEPV1, JRA55, and CRA40 being significantly larger in August than in other months. The cold biases of the REAs (in particular NCEPV2, CFSR, and ERA5) are larger in spring and winter than in summer and autumn. We think the urbanization bias of observational data is higher in winter than that of in summer. The REAs assimilated the homogeneous observational data which ignored the bias caused by the urbanization. Thus, the REAs may overestimate the temperature in winter.

Figure 3. The bias of monthly mean SAT between REAs and OBS from 1961-2015 across mainland China: (a) NCEPV1; (b) JRA55; (c) 20CRV3; (d) CRA40; (e) NCEPV2; (f) ERA5; (g) CFSR; (h) MERRA. (The value of color bar means the monthly mean SAT bias (units: ${ }^{\circ} \mathrm{C}$ ))

Wavelet analysis is one of the important methods used to detect periodic characteristics of climatic series (Weng et al., 1994). The result of wavelet transform is shown in Figure 4. There are approximately 2.5-5 year periodic characteristics in the SAT data series of the OBS and REAs from 1990-2000. The 20CRV3 indicated the 2.5-5 year periodic characteristics in the 1980s, which is different from those of the other REAs. Overall, the REAs can describe the periodic characteristics of air temperature variability in the 1990s to a certain extent, but the signals are generally weak for the period before the 1980s, with the exception of 20CRV3.

Figure 4. Wavelet analysis based on REAs and OBS from 1961-2015: (a) NCEPV1; (b) JRA55; (c) 20CRV3; (d) CRA40; (e) NCEPV2; (f) ERA5; (g) CFSR ; (h) MERRA ; (i) OBS. 
The climate state and linear trend of SAT are important indicators in climate research derived by the REAs and OBS. Figure 5 and Table 2 show the histograms of annual mean SAT values and linear trends for the periods 1961-2015 and 1979-2015. The mean SAT of the REAs is generally $0-2.0^{\circ} \mathrm{C}$ lower than the OBS during $1961-2015$. The linear trend of the OBS is $0.191^{\circ} \mathrm{C} / 10$ years. Linear trends of the REAs and OBS are all statistically significant at the $95 \%$ level. Table 4 shows that the SAT trends of NCEPV1 and JRA55 are 4.0\% and 10.5\% higher than the OBS, respectively. In addition, 20CRV3 is $11 \%$ lower than the OBS. The annual mean SAT of the OBS is generally $0.2-1.93^{\circ} \mathrm{C}$ higher than the REAs from 1979 to 2015 and CRA40 is $0.3 \%$ lower than the OBS. The trends of 20CRV3 and CRA40 are consistent with the OBS. Moreover, CFSR and NCEPV1 are closer to the OBS than JRA55 in terms of linear trends. Therefore, 20CRV3 and CRA40 are generally consistent with the OBS for the climate state from 1961-2015 and 1979-2015, respectively, and NCEPV1 and 20CRV3 are more similar to the OBS than the other REAs for the linear trends from 1961-2015 and 1979-2015, respectively. The annual mean SAT linear trends also exhibit an obvious difference from those of the previous analyses. Zhou et al. (2018) report that the linear trends of REAs was about $0-0.15^{\circ} \mathrm{C} / 10$ years higher than those of SAT without the urbanization bias adjustment (the relative bias between the REAs and OBS was about $0-40 \%$ in 1979-2010), but in this study, the relative bias between the REAs and OBS in 1979-2015 was about $0-30 \%$, with generally more difference from those of the previous analyses.

We also evaluate the bias of climate state and linear trend of seasonal mean SAT across China derived from REAs and OBS for the periods 1961-2015 and 1979-2015 (Figure omitted). The seasonal mean SAT of the REAs is generally $0-2^{\circ} \mathrm{C}$ lower than the OBS. The climate state bias of NCEPV1, JRA55 and CRA40 in summer is generally larger than those of in other season during 1961-2015 and 1979-2015. For example, the bias of NCEPV1 in summer is -2.172 in 1961-2015 and -2.083 in 1979-2015, which is more lager than other season. The bias of linear trends in summer for NCEPV1 and 20CRV3 during 1961-2015 is larger than those of in other season. But in 19792015, NCEPV1, 20CRV3, NCEPV2 and MERRA are more consistent with the OBS in summer. In addition, the biases of climate state and linear trend of seasonal mean SAT across China indicate that the climate state and linear trends bias in summer are significant difference during 1961-2015. But the linear trends bias in 1979-2015, a part of REAs are consistent with OBS in summer than those of in winter.

Figure 5. Annual mean SAT and annual mean SAT linear trends for the periods 1961-2015 and 1979-2015. (The red bar stand for climate state (units: ${ }^{\circ} \mathrm{C}$ ), the orange bar stand for linear trends (units: ${ }^{\circ} \mathrm{C} / 10$ years))

Table 2. Relative bias between the REAs and OBS for climate state and linear trends for the periods 1961-2015 and 1979-2015.

We also compare the similarity of correlation and standard deviation ratio between REAs and OBS for the periods 1961-2015 and 1979-2015 in order to evaluate the credibility of the REAs in terms of inter-annual variability and dispersion.

Table 3 lists the correlation coefficient $(\mathrm{R})$ and standard deviation ratio (SDR) between the annual mean SATs of REAs and OBS over the periods 1961-2015 and 1979-2015. The R values are statistically significant from 1961-2015 ( $p<0.05)$. The R of JRA55 is higher than that of either 20CRV3 or NCEPV1. The standard deviations (STDs) of the REAs are higher than those of the 
OBS from 1961-2015. 20CRV3 is more consistent with the OBS in terms of dispersion. The REAs reflect the inter-annual and decadal variability of the regional surface air temperature to a large extent, particularly from 1979-2015, when R $>0.9$. The R of ERA5 was 0.997 , indicating the most similar variability to the OBS. JRA55, NCEPV1, and CRA40 also exhibit higher credibility in terms of inter-annual and decadal variability. The STDs of MERRA and NCEPV2 are lower than those of the OBS, whereas the STDs of the other REAs are higher than those of the OBS. The STDs of NCEPV2 and JRA55 are more in agreement with the OBS, while NCEPV1 and MERRA displayed higher dispersions from observations for the period 1979-2015. Zhou et al. (2018) report that the SDR value is $0.5-0.8$, indicating a lower variability of the REAs than the OBS. Since the STD of the OBS is somehow lowered when the data were adjusted for urbanization bias, due to the adjustment method used (Wen et al., 2019), the STDs of the REAs look generally more similar to those of the OBS in this research.

Table 3. Standard deviation ratio (SDR) and correlation coefficient (R) of annual mean SAT across China derived from REAs and OBS for the periods 1961-2015 and 1979-2015 (thresholds for the $95 \%$ confidence level are 0.26 and 0.32 respectively)

We also evaluate the SDR and R of seasonal mean SAT across China derived from REAs and OBS for the periods 1961-2015 and 1979-2015. The R values of seasonal mean SAT are statistically significant from 1961-2015 and 1979-2015 respectively (Figure omitted). Most of R values are $0.9-1.0$, indicating the most similar variability to the OBS. The $\mathrm{R}$ values of NCEPV1 $(\mathrm{R}=0.851)$ and 20CRV3 $(\mathrm{R}=0.879)$ in summer are lower than those of in other seasons during 1961-2015. $\mathrm{CFSR}(\mathrm{R}=0.906)$, MERRA $(\mathrm{R}=0.917)$ and 20CRV3( $\mathrm{R}=0.858)$ in summer are lower than those of in other seasons during 1979-2015. Most of STDs for REAs are higher than those of the OBS during 1961-2015. Conversely, the SDR values of NCEPV1, NCEPV2 and MERRA in spring and summer are lower than 1.0 during 1979-2015. Overall, the SDR and R of seasonal mean SAT in autumn and winter are more in agreement with the OBS in spring and summer.

\subsection{Spatial characteristics}

Figures 6-8 illustrate the spatial distribution of the climate state and linear trends for the periods 1961-2015 and 1979-2015. The cold biases $\left(>2^{\circ} \mathrm{C}\right)$ of SAT between the REAs and OBS are significant $(\mathrm{p}<0.05)$ in portions of western and eastern China from 1979-2015 (Figure 6). The annual mean temperatures of MERRA, ERA5, 20CRV3 and CRA40 show a significant warm bias $(\mathrm{p}<0.05)$ in regions of northern and northeastern China. The bias between CRA40 or MERRA and the OBS is above $3^{\circ} \mathrm{C}$ in most stations of northern China. The different characteristics between the REAs (NCEPV1, JRA55, and 20CRV3) and OBS during 1979-2015 are similar to those of 1961-2015 (Figure omitted). Overall, there are significant cold biases between the REAs and OBS over western and southern China and warm biases in northern China.

Figure 6. Spatial distribution of annual mean SAT bias of REAs from observations for the period 1979-2015 across mainland China: (a) NCEPV1; (b) JRA55; (c) 20CRV3; (d) CRA40; (e) NCEPV2; (f) ERA5; (g) CFSR; (h) MERRA.

(The black dots represent significant deviation, the value of color bar means the annual mean SAT bias (units: $\left.{ }^{\circ} \mathrm{C}\right)$ ) 
The spatial distributions of linear trend for the periods 1961-2015 show that the trend of NCEPV1 is significantly higher in general than the OBS over central and eastern China (Figure 7). There is a significantly cold trend bias in western China and part of northern China, with the trend biases of some stations $>0.6^{\circ} \mathrm{C} / 10$ years, but the country average bias (4.18\%) between NCEPV1 and the OBS is lower than that of the other REAs (Table 4). This indicates that the larger cold bias in western China reduced the overall warm bias across China. The linear trend of JRA55 is higher than the OBS, whereas 20CRV3 is generally lower in most areas of China. The trends of OBS in northern and western China are warmer than those of in central and southern China. Figure 8 shows that the trends of NCEPV1, NCEPV2, and MERRA are lower than the OBS over most parts of China from 1979 to 2015 , with bias values of $-9.2 \%, 30.5 \%$, and $26.2 \%$, respectively, as listed in Table 2. These three REAs are significantly cold bias over parts of central and western China as well as northern and eastern China. The trends of the other REAs (JRA55, ERA5, CFSR, 20CRV3, and CRA40) are higher than those the OBS. JRA55 and ERA5 are characterized by the warm bias over northern, eastern, southwestern, and northeastern China. CFSR, 20CRV3 and CRA40 have warm trend bias over southern, southwestern, and northeastern China.

Figure 7. Spatial distribution of linear trend of OBS and linear trend bias between REA and OBS for the period 1961-2015 across China:(a) NCEPV1; (b) JRA55; (c) 20CRV3 (d) OBS. (The black dots represent significant deviation, the value of color bar means the linear trend bias and linear trend (units: ${ }^{\circ} \mathrm{C} / 10$ year))

Figure 8. Spatial distribution of linear trend bias between REA and OBS for the period 1979-2015 across China:(a) NCEPV1; (b) JRA55; (c) 20CRV3; (d) CRA40; (e) NCEPV2; (f) ERA5; (g) CFSR; (h) MERRA.

(The black dots represent significant deviation, the value of color bar means the linear trend bias (units: ${ }^{\circ} \mathrm{C} / 10$ year))

Figures 9 and 10 show the relationship of biases of climate state and linear trends of annual mean SAT for different REAs with varied elevation. The biases of annual mean SAT in highaltitude regions (especially above $3000 \mathrm{~m}$ ) are higher than those at low altitudes. Even though there is a cold mean temperature bias between the REAs and OBS, the number of JRA55 stations which are close to the OBS trend values, are larger than those of NCEPV1 and 20CRV3 for the period 1961-2015 and the NCEPV1 witnessing the most stations with large biases. The bias distribution characteristics of REAs for the period 1979-2015 are similar to those for the period 1961-2015. ERA5 and JRA55 are more consistent with the OBS with regard to both climate state and linear trends. 20CRV3 seems to have a smaller bias of annual mean trends than any other REAs. The biases of linear trends in high-altitude regions (especially above $2000 \mathrm{~m}$ ) are significantly higher than those of low-altitude regions.

The linear trends of NCEPV1, JRA55 and 20CRV3 are more consistent with those of the OBS during 1979-2015 than during 1961-2015. Since the cold biases at low altitudes and the warm biases at high altitudes are significant, the spatial distribution of the linear trend for NCEPV1 is not as well-defined as those of JRA55 and 20CRV3. From 1979 to 2015, the biases of both climate state and linear trends for CRA40, JRA55, 20CRV3, and ERA5 are obviously lower than those of the other REAs (NCEPV2, CFSR, and MERRA) which exhibit significant bias at high altitudes. 
This indicates that the larger SAT biases of the reanalysis data primarily occurs in higher areas including the Qinghai-Tibetan Plateau. The reason may be related to fact that there is a large uncertainty with the numerical prediction model and the assimilation schemes with rising elevation. On the other hand, the elevation differences (station minus model grid) are negative, probably because most observational stations are located in the flat ground or valley bottom, which is lower than the reanalysis model topography. This contrast could also lead to a large temperature difference.

Figure 9. The biases of climate state and linear trends of annual mean temperature between REAs and OBS for the period 1961-2015. (a) NCEPV1; (b) JRA55; (c) 20CRV3.

(The asl stands for elevation (units: $\mathrm{m}$ ); $\mathrm{y}$-axis stand for the bias of climate state (units: ${ }^{\circ} \mathrm{C}$ ); $\mathrm{x}$-axis stand for the bias of linear trends (units: ${ }^{\circ} \mathrm{C} / 10$ years); red bar stand for the number of stations with different bias of linear trends; blue bar stand for the number of stations with different bias of climate state; purple dots represent the altitude of stations above $3000 \mathrm{~m}$; blue dots represent the altitude of stations between 1500-3000m; orange dots represent the altitude of stations between $500-1500 \mathrm{~m}$; green dots represent the altitude of stations less than $500 \mathrm{~m}$ )

Figure 10. The biases of climate state and linear trends of annual mean temperature between the REAs and OBS for the period 1979-2015. (a) NCEPV1; (b) JRA55; (c) 20CRV3; (d) CRA40; (e) NCEPV2; (f) ERA5; (g) CFSR; (h) MERRA.

(The asl stands for elevation (units: $\mathrm{m}$ ); $\mathrm{y}$-axis stand for the bias of climate state (units: ${ }^{\circ} \mathrm{C}$ ); $\mathrm{x}$-axis stand for the bias of linear trends (units: ${ }^{\circ} \mathrm{C} / 10$ years); red bar stand for the number of stations with different bias of linear trends; blue bar stand for the number of stations with different bias of climate state; purple dots represent the altitude of stations above $3000 \mathrm{~m}$; blue dots represent the altitude of stations between 1500-3000m; orange dots represent the altitude of stations between $500-1500 \mathrm{~m}$; green dots represent the altitude of stations less than $500 \mathrm{~m}$ )

In order to examine the performance of the REAs in high-altitude regions, Figure 11, Figure 12, and Table 4 present the R and SDR characteristics between the REAs and OBS of annual mean SAT for 763 stations across mainland China. They show that The R value of most REA stations could describe the inter-annual variability $(\mathrm{p}<0.05)$ from 1979-2015 to a large extent. With increasing elevation, however, the $\mathrm{R}$ value of the REAs $(\mathrm{R}>0.8)$ decreased. The $\mathrm{R}$ value of JRA55 is generally higher than those of the other REAs. Although NCEPV1, NCEPV2, CFSR, MERRA, and CRA40 have higher correlations with the OBS at low altitudes, they are not so good at high altitudes. The $R$ values of some stations above $1500 \mathrm{~m}$ are not statistically significant $(\mathrm{p}>0.05)$ for NCEPV2, CFSR, and MERRA. R value of NCEPV2 is lower than those of the other REAs from 3000-5000 m. The SDR value between the REAs (NCEPV2, CRA40, ERA5, and CFSR) and the OBS stations increase with increasing elevation. The STDs of NCEPV1 and MERRA are lower than those of the OBS at high altitudes. In addition, JRA55 is generally closer to the OBS than the other REAs from 0-5000 m. The R values between JRA55 and the OBS for period 1961-2015 are consistent with those for period 1979-2015, indicating a higher similarity than NCEPV1 and 20CRV3 to the observations. With rising elevation, the SDR value of 20CRV3 is also more consistent with the OBS from 1961-2015, but this may imply an underestimate considering the observed data which have been adjusted for urbanization bias. 
Figure 11. Taylor diagrams of annual mean SAT for 763 stations across mainland China derived by the REAs and OBS for the period 1961-2015: (a) NCEPV1; (b) JRA55; (c) 20CRV3.

(The asl stands for elevation (units: $\mathrm{m}$ ), the purple dots represent the altitude of stations above $3000 \mathrm{~m}$. The blue dots represent the altitude of stations between $1500-3000 \mathrm{~m}$. The orange dots represent the altitude of stations between $500-1500 \mathrm{~m}$. The green dots represent the altitude of stations less than $500 \mathrm{~m}$, threshold for the $95 \%$ confidence level is 0.26 )

429

430

Figure 12. Taylor diagrams of annual mean SAT for 763 stations across mainland China derived by the REAs and OBS for the period 1979-2015:(a) NCEPV1; (b) JRA55; (c) 20CRV3; (d) CRA40; (e) NCEPV2; (f) ERA5; (g) CFSR; (h) MERRA.

(The asl stands for elevation (units: $\mathrm{m}$ ), the purple dots represent the altitude of stations above $3000 \mathrm{~m}$. The blue dots represent the altitude of stations between 1500-3000m. The orange dots represent the altitude of stations between 500-1500m. The green dots represent the altitude of stations less than $500 \mathrm{~m}$, threshold for the $95 \%$ confidence level is 0.32 )

Table 4. R and SDR values between the REAs and OBS at different elevations for the periods 1961-2015 and 1979-2015.

The above results indicate that REA for most stations reproduce the inter-annual variability and dispersion from 1961-2015 and 1979-2015 to a large extent. With rising elevation, the R values of the REAs with observations decreased, whereas the SDR values increased. JRA55 is closer to the OBS than the other REAs. The reason that NCEPV2 or CFSR and the OBS are significantly different may be related to the numerical prediction model and the assimilation schemes.

\subsection{Comprehensive evaluation and discussion}

The applicability and credibility of reanalysis data differ in various research directions of climate and climate change. REAs need to be chosen according to particular research purposes. However, it is necessary to pay more attention to linear trends for climate change research and inter-annual variability or deviations for climatological characteristics analysis in evaluation of the REAs application. Using the urbanization bias-adjusted OBS as the reference, we perform a comprehensive sorting of the REAs in terms of their goodness in reproducing the inter-annual variability, dispersion, climate state and linear trend. The separate and integrated rankings of the REAs for the periods 1961-2015 and 1979-2015 are shown Table 5.

Table 5. Ranking and score of each of the reanalysis datasets in mainland China for the periods 1961-2015 and 1979-2015.

It is interesting to note that, CRA40, which assimilate high-density domestic and overseas observational data and satellite data, is closer to the OBS than the other REAs, during the common period of 1979-2015. Although there is still biases in terms of inter-annual variability, dispersion and linear trends, which may have been related to the assimilation scheme, CRA40 have the highest integrated scores (95.8) among the eight REAs. In addition, NCEPV1, JRA5 and ERA55 display better performance than most REAs in various aspects in mainland China during 1979-2015, with the relatively high scores of $94.2,93.7$ and 93.5 respectively. The goodness of JRA55 and ERA5 
has been attributed to the assimilation of the SAT data and the improved model systems compared to the old generation (JRA25 and ERA-interim). NCEPV1 with priority in dispersion display a lower reliability in climate state during 1979-2015 and 1961-2015. The integrated score of 20CRV3 was 92.5 and 93.5 during the periods of 1979-2015 and 1961-2015 respectively, with the better performance than other REAs in linear trend (1979-2015), dispersion (1961-2015), and climate state (1961-2015). It is also clear that the biases of MERRA, CFSR and NCEPV2 are generally higher than those of the other REAs. If no substantial improvement is made, they are not applicable in studies of climate and climate change over mainland China.

A few futures previously found are now explainable from this paper. Zhu et al. (2015) discovered that the cold bias of the ERA-interim was higher in summer than in other seasons in China. The current study reveals that the bias between ERA5 and OBS is lower in summer than in other seasons, indicating that the seasonal mean SAT of ERA5 has a good credibility actually in mainland China. This similarity may have been related to the substantial adjustment of mean temperature in summer months in central and southern North China in the new dataset (Wen et al., 2019). The SAT in JRA55 is the post-processing product by analysis scheme in surface and lowest model level and observations of SAT, with the help of Monin-Obukhov similarity profiles consistent with the model's parameterization of the surface layer (Kobayashi et al., 2015). Kistler (1998) show that the SAT of NCEPV1 before 1967 had a drawback similar to that of "PSFC" (the error caused by the assimilation of surface air pressure from 1948-1967 led to significant deviation), indicating that it is not suitable for analyzing the climate characteristic before 1967. Our analysis confirms the conclusion, indicating that NCEPV1 has a large fluctuation from 19611968, and although the dataset describe the annual climate variability and dispersion well, it is not suitable for either the climate state analysis in terms of the comparison with the new observations of both periods 1979-2015 and 1961-2015.

Zhang et al. (2019) found that the annual mean SAT of 20CRV2C had an abnormally large fluctuation from 1963-1968. Zhou et al. (2018) demonstrated that the R value between the old generation 20CR (20CRV2 and 20CRV2C) and the OBS was 0.8-0.9 from 1979-2010. Our analysis show that the annual mean SAT variability and R value of 20CRV3 are more consistent with the OBS in the 1960s than the previous versions (20CRV2 and 20CRV2C), demonstrating an obvious improvement in the new generation of 20CR. 20CRV3, however, is still unsatisfactory because it is unable to reproduce all of the SAT characteristics compared to JRA55, ERA5 and CRA40 during 1979-2015. The reasons for the larger biases with MERRA, NCEPV2, and CFSR need to be further investigated. With improving accurate of land surface conditions and applying more advance climate assimilation system, these datasets also need to assimilate and analyze observation, satellite radiance and other remote datasets, and to advance the simulation of landatmosphere interactions to yield high-quality new-generation reanalysis for potential use in studies of global and regional climate change (Herring et al., 2018; Trenberth et al., 2015; Zhou and Wang, 2017b).

\section{Conclusions}

Based on the urbanization bias-adjusted data obtained from 763 stations and 8 sets of surface air SAT reanalysis data during the periods 1961-2015 and 1979-2015, we utilize time series, period features, correction values, dispersion values, and linear trends to comprehensively evaluate the suitability and credibility of the reanalysis data for studies of climatological characteristics and 
climate change over mainland China. Main conclusions are as follows.

(1) The SATs of the REAs are generally lower than those of the OBS from 1961-2015. The cold biases of CRA40, NCEPV1 and JRA55 are mainly caused by the lower SAT in summer, whereas those of NCEPV2, CFSR, and ERA5 are mainly caused by the lower winter mean temperature. The time series of CRA40 and JRA55 are more consistent with the OBS during the two periods of 1979-2015 and 1961-2015 respectively. The annual mean REAs can well describe to a large extent the 2.5-5 year periodical characteristics as revealed in OBS.

(2) The country average annual mean reanalysis SAT is generally $0-2^{\circ} \mathrm{C}$ lower than the observational data. The linear trends of annual mean SAT of all the reanalysis and observational data exhibit clear warming during 1961-2015 and 1979-2015. The biases in the annual mean SAT derived by the REAs (20CRV3 and CRA40) are lower than those of the other reanalysis data for 1961-2015 and 1979-2015, and the linear trends of NCEPV1 and 20CRV3 are closer to those of the observations for the two periods evaluated.

(3) The REAs can reproduce to a large extent the inter-annual variability and dispersion for the periods 1961-2015 and 1979-2015. The inter-annual SAT variability of JRA55 and ERA5 are generally closer to the observations. The dispersions of 20CRV3 and NCEPV1 are more consistent with the observations.

(4) The REA biases in correlation, standard deviation, climate state and linear trends generally increase with increasing elevation of stations. The $\mathrm{R}$ values for some stations above $1500 \mathrm{~m}$ for the REAs are not significant $(p>0.05)$, indicating the disability to describe the inter-annual variability of annual mean SAT in the Qinghai-Tibetan Plateau.

(5) Comprehensive sorting of the REA datasets show the higher scores of CRA40, NCEPV1, ERA5 and JRA5, indicating the better performance of the products in reproducing various aspects of climatological and climate change features in mainland China, and their applicability in monitoring and studies of climate variability and change in the country. 
The authors declared that they have no conflicts of interest to this work. We declare that we do not have any commercial or associative interest that represents a conflict of interest in connection with the work submitted.

\section{Funding Statement}

This study is financed by the National Key Research and Development Program of China

544 (2018YFA0605603), the construction project of weather modification in the Northwest China from

545 China Meteorological Administration (RYSY201907), China Natural Science Foundation (CNSF)

546 (41801017), China Meteorological Administration Special Foundation for Climate Change

547 (CCSF201902) and Special Fund for Meteorological Scientific Research in the Public Interest 548 (GYHY 201506002).

549

\section{Author's Contribution}

Siqi Zhang conducted the analysis and writing of the article. Guoyu Ren designed the analysis

552 and revised the manuscript. Yuyu Ren and Yingxian Zhang was involved in the revision and analysis of the article. Xiaoying Xue helped with drawing of the figures.

554 


\section{Reference}

Bengtsson L, Hagemann S, Hodges KI. 2004. Can climate trends be calculated from reanalysis data? J Geophys Res, 109(11): 839-856.

Borgia L, Valberg S, Mccue M, Watts K, Pagan J. 2004. Sensitivity of the ERA40 reanalysis to the observing system: Determination of the global atmospheric circulation from reduced observation. Tellus Series A-dynamic Meteorology \& Oceanography, 56(5): 456-471.

Cao L, Yan Z, Zhao P, Zhu Y, Yu Y, Tang G, Jones P. 2017. Climatic warming in China during 1901-2015 based on an extended dataset of instrumental temperature records. Environmental Research Letters, 12(6): 4384-4392.

Compo GP, Whitaker JS, Sardeshmukh PD, Matsui N, Allan RJ, Yin X, Gleason BE, Vose RS, Rutledge G, Bessemoulin P. 2011. The Twentieth Century Reanalysis Project. Quarterly Journal of the Royal Meteorological Society, 137(654): 1-28.

Dee DP, Balmaseda M, Balsamo G, Engelen R, Simmons AJ, Thépaut JN. 2014. Toward a Consistent Reanalysis of the Climate System. Bulletin of the American Meteorological Society, 95(8): 1235-1248. https://doi.org/10.1175/BAMS-D-13-00043.1.

Dee DP, Uppala SM, Simmons AJ, Berrisford P, Poli P, Kobayashi S, Andrae U, Balmaseda MA, Balsamo G, Bauer P. 2011. The ERA - Interim reanalysis: configuration and performance of the data assimilation system. Quarterly Journal of the Royal Meteorological Society, 137(656): $553-597$.

Fan K, Liu H. 2013. Evaluation of Atmospheric Circulation in the Southern Hemisphere in 20CRv2. Atmospheric and Oceanic ence Letters, 6(005): 337-342.

Gao Q, Guan Z, Cai J, Min J. 2010. Differences in 1958 - 2001 Summertime Surface Air Temperatures between Two Reanalysis Data and Observations in China. J. Meteor. Sci., 34(3): $471-482$.

Hersbach H, Bell B, Berrisford P, Hirahara S, Horányi A, Muñoz-Sabater J, Nicolas J, Peubey C, Radu R, Schepers D, Simmons A, Soci C, Abdalla S, Abellan X, Balsamo G, Bechtold P, Biavati G, Bidlot J, Bonavita M, De Chiara G, Dahlgren P, Dee D, Diamantakis M, Dragani R, Flemming J, Forbes R, Fuentes M, Geer A, Haimberger L, Healy S, Hogan RJ, Hólm E. A, Janisková M, Keeley S, Laloyaux P, Lopez P, Radnoti G, Rosnay P D, Rozum I, Vamborg F, Villaume S, Thépaut J-N. 2020.The ERA5 global reanalysis. Q J R Meteorol Soc (submitted).

He Y, Jia G, Hu Y, Zhou Z. 2013. Detecting urban warming signals in climate records. Adv. Atmos. Sci., 30(4): 1143-1153.

Herring SC, Nikolaos C, Andrew H, Kossin JP, Schreck CJ, Stott PA. 2018. Explaining Extreme Events of 2016 from a Climate Perspective. Bulletin of the American Meteorological Society, 99(1): S1-S157.

Hua L, Ma ZG, Guo WD. 2008. The impact of urbanization on air temperature across China. Theoretical and Applied Climatology, 93(3-4): 179-194. https://doi.org/10.1007/s00704-0070339-8.

Janis MJ, Hubbard KG, Redmond KT. 2004. Station density strategy for monitoring longterm climate change in the contiguous United States. J. Climate, 17: 151-162.

Kalnay E, Kanamitsu M, Kistler R, Collins W, Deaven D, Gandin L, Iredell M, Saha S, White G, Woollen J. 1996. The NCEP/NCAR 40-Year Reanalysis Project. Bull.amer.meteor Soc, 77(3): $437-472$.

Kanamitsu M, Ebisuzaki W, Woollen J, Yang SK, Hnilo JJ, Fiorino M, Potter GL. 2002. NCEP_- 
DOE AMIP-II Reanalysis (R-2). Bulletin of the American Meteorological Society, 83(11): 16311643 .
Kistler
R. 1998.
Reanalysis
PSFC
problem
1948-1967. http://wwwt.emc.ncep.noaa.gov/gmb/ bkistler/psfc/psfc.html.

Kistler R, Collins W, Saha S, White G, Woollen J, Kalnay E, Chelliah M, Ebisuzaki W, Kanamitsu M, Kousky V. 2001. The NCEP-NCAR 50-Year Reanalysis: Monthly Means CDROM and Documentation. Bulletin of the American Meteorological Society, 82(2): 247-268.

Kobayashi S, Ota Y, Harada Y, Ebita A, Moriya M, Onoda H, Onogi K, Kamahori H, Kobayashi C, Endo H. 2015. The JRA-55 Reanalysis: General Specifications and Basic Characteristics. Journal of the Meteorological Society of Japan.ser.i, 93(1): 5-48.

Lahoz WA, Schneider P. 2014. Data assimilation: making sense of Earth Observation. Atmospheric Science, 2: 16.

Li Q, Li W, Si P, Gao X, Dong W, Jones P, Huang J, Cao L. 2010. Assessment of surface air warming in northeast China, with emphasis on the impacts of urbanization. Theoretical \& Applied Climatology, 99(3-4): P.469-478.

Li R, Li S, Han B, Gao YH. 2012. Preliminary Comparison and Analyses of Air Temperature at $2 \mathrm{~m}$ Height between Three Reanalysis Data-Sets and Observation in the East of Qinghai-Xiang Plateau. Plateau Meteorology, 31(6): 1488-1502.

Li Z, Cao L, Zhu Y, Yan Z. 2015. Comparing Two Homogenized Datasets of Daily Maximum/Mean/Minimum Temperatures in China During 1960-2013. J. Meteor. Res., 30: 53-66. https://doi.org/doi: 10.1007/s13351-016-5054-x.

Liang X, Li P, et al. 2020. A 10-Yr Global Land Surface Reanalysis Interim Dataset (CRAInterim/Land):Implementation and Preliminary Evaluation. Journal of Meteorological Research, 34(01):104-119.

Lindsay R, Wensnahan M, Schweiger A, Zhang J. 2014. Evaluation of Seven Different Atmospheric Reanalysis Products in the Arctic. Journal of Climate, 27(7): 2588-2606.

Liu J, Zhang Z, Hu Y, Chen L, Dai Y, Ren X. 2008. Assessment of surface air temperature over the Arctic Ocean in reanalysis and IPCC AR4 model simulations with IABP/POLES observations. Journal of Geophysical Research, 113(D10): 105. https://doi.org/10.1029/2007JD009380.

Ma L, Zhang T, Li Q, Frauenfeld OW, Qin D. 2008. Evaluation of ERA-40, NCEP-1, and NCEP-2 reanalysis air temperatures with ground-based measurements in China. Journal of Geophysical Research, 113(D15). https://doi.org/10.1029/2007JD009549.

Parker WS. 2016. Reanalyses and observations : what's the di erence. Bulletin of the American Meteorological Society, 97(9): 1565-1572.

Ren G, Zhou Y. 2014. Urbanization Effect on Trends of Extreme Temperature Indices of National Stations over Mainland China, 1961-2008. Journal of Climate, 27(6): 2340-2360. https://doi.org/10.1175/JCLI-D-13-00393.1.

Ren G, Zhou Y, Chu Z, Zhou J, Zhang A, Guo J, Liu X. 2008. Urbanization Effects on Observed Surface Air Temperature Trends in North China. Journal of Climate, 21(6): 1333-1348.

Ren GY, Chu ZY, Chen ZH, Ren YY. 2007. Implications of temporal change in urban heat island intensity observed at Beijing and Wuhan stations. Geophysical Research Letters, 34(5): 89103.

Ren GY, Zhang AY, Chu ZY, Zhou JX, Zhou YQ. 2010. Principles and Procedures for Selecting Reference Surface Air Temperature Stations in China. Meteor. Sci. Tech., 38: 78-85. 
Ren Y, Ren G. 2011. A Remote-Sensing Method of Selecting Reference Stations for Evaluating Urbanization Effect on Surface Air Temperature Trends. Journal of Climate, 24(13): 3179-3189. https://doi.org/10.1175/2010JCLI3658.1.

Ren Y, Ren G, Zhou J. 2012. The Ideal Density and Distribution of China Climate Network for Monitoring Surface Climate Change. Journal of Applied Meteorological Science, 23: 205-213.

Ren Y, Ren Guoyu, Zhang Lei, Zhou Y, Zhang A. 2015. An Integrated Procedure to Determine a Reference Station Network for Evaluating and Adjusting Urban Bias in Surface Air Temperature Data. Journal of Applied Meteorology and Climatology, 54: 1248-1266.

Rienecker MM, Suarez MJ, Gelaro R, Todling R, Bacmeister J, Liu E, Bosilovich MG, Schubert SD, Takacs L, Kim GK. 2011. MERRA: NASA's Modern-Era Retrospective Analysis for Research and Applications. Journal of Climate, 24(14): 3624-3648.

Saha S, Moorthi S, Pan HL, Wu XR, Wang JD, Nadiga S, Tripp P, Kistler R, Woollen J, Behringer D. 2010. The NCEP climate forecast system reanalysis. Bulletin of the American Meteorological Society, 91(8): 1015-1057.

Stefan B, Yuri B, Rob J A, et al. 2018 A roadmap to climate data rescue services. Geoscience Data Journal, 5(1), 28-39. DOI: 10.1002/gdj3.56

Shi T, Huang Y, Wang H, Shi CE, Yang YJ. 2015. Influence of urbanization on the thermal environment of meteorological station: Satellite-observed evidence. Advances in Climate Change Research, 6(1): 7-15.

Slivinski LC, Compo GP, Whitaker JS, Sardeshmukh PD, Giese BS, McColl C, Allan R, Yin X, Vose R, Titchner H, Kennedy J, Spencer LJ, Ashcroft L, Brönnimann S, Brunet M, Camuffo D, Cornes R, Cram TA, Crouthamel R, Domínguez Castro F, Freeman JE, Gergis J, Hawkins E, Jones PD, Jourdain S, Kaplan A, Kubota H, Blancq FL, Lee TC, Lorrey A, Luterbacher J, Maugeri M, Mock CJ, Moore GWK, Przybylak R, Pudmenzky C, Reason C, Slonosky VC, Smith CA, Tinz B, Trewin B, Valente MA, Wang XL, Wilkinson C, Wood K, Wyszyński P. 2019. Towards a more reliable historical reanalysis: Improvements for version 3 of the Twentieth Century Reanalysis system. Quarterly Journal of the Royal Meteorological Society, 145(724): 2876-2908. https://doi.org/10.1002/qj.3598.

$\mathrm{Su} \mathrm{Z}, \mathrm{Lv}$ S, Luo S. 1999. The examination and analysis of NCEP/NCAR 40 year global reanalysis data in China. Plateau Meteor., 18(2): 209-218.

Tang G, Ren G. 2005. A reanalysis of surface air temperature change of the last 100 years in China. Climatic. Environ. Res., 10(4): 791-798.

Thorne WP, Vose SR. 2010. REANALYSES SUITABLE FOR CHARACTERIZING LONGTERM TRENDS. Bulletin of the American Meteorological Society, 91: 353-361.

Trenberth KE, Fasullo JT, Shepherd TG. 2015. Trenberth K E, Fasullo J T , Shepherd T G . Attribution of climate extreme events. , 2015, 5(8):725-730. Nature Climate Change, 5(8): 725730 .

Wang F, Ge QS. 2012. Estimation of urbanization bias in observed surface temperature change in China from 1980 to 2009 using satellite land use data. Chin. Sci. Bull., 057(011): 951-958.

Wen K, Ren G, Li J, Zhang A, Ren Y, Sun X, Zhou Y. 2019. Recent Surface Air Temperature Change over Mainland China Based on an Urbanization-Bias Adjusted Dataset. Journal of Climate, 32(10): 2691-2705. https://doi.org/10.1175/JCLI-D-18-0395.1.

Weng H. 1994. Wavelets, Period Doubling, and Time-Frequency Localization with Application to Organization of Convection over the Tropical Western Pacific. Journal of the Atmospheric 
Sciences, 51: 2523-2541.

Xu Y, Ding Y. 2001. Confidence analysis of NCEP/NCAR 50-year global reanalyzed data in climate change research in China. Quarterly Journal of Applied Meteorlolgy, 12: 337-347.

Zhang A, Ren G. 2009. Detection and correction of urbanization bias to national station data series of surface air temperature. Chin. Aca. Meteor. Sci., 60pp.

Zhang A, Ren G, Zhou J, Chu Z, Ren Y, Tang G. 2010. Urbanization effect on surface air temperature trends over China. Acta Meteor. Sin, 68(06): 197-206.

Zhang S, Ren G, Ren Y, Sun X. 2019. Comparison of Surface Air Temperature between Observation and Reanalysis Data over Eastern China for the Last 100 Years. J. Meteor. Soc. Japan, 97(4): 89-103. https://doi.org/10.2151/jmsj.2019-004.

Zhao TB, Fu C. 2006. preliminary comparison and analysis between ERA40, NCEPV2 reanalysis and observation over China. Climatic and Environmental Research, 11(1): 14-32.

Zhao T, Fu C, Ke Z, Guo W. 2010. Global Atmosphere Reanalysis Datasets:Current Status and Recent Advances. Advances in Earth Science, 25(3): 242-254.

Zhao T, Wang J, Dai A. 2015. Evaluation of atmospheric precipitable water from reanalysis products using homogenized radiosonde observations over China. Journal of Geophysical Research Atmospheres, 120(20). https://doi.org/doi:10.1002/2015JD023906.

Zhou C, He Y, Wang K. 2018. On the suitability of current atmospheric reanalyses for regional warming studies over China. Atmospheric Chemistry and Physics, 18(11): 8113-8136. https://doi.org/10.5194/acp-18-8113-2018.

Zhou C, Wang K. 2016. Land surface temperature over global deserts: Means, variability, and trends. Journal of Geophysical Research Atmospheres, 121(24): 14,344-14,357.

Zhou C, Wang K. 2017. Quantifying the Sensitivity of Precipitation to the Long-Term Warming Trend and Interannual-Decadal Variation of Surface Air Temperature over China. Journal of Climate, 30: 3687-3703. https://doi.org/10.1175/jcli-d-16-0515.1.

Zhou C, Wang K, Ma Q. 2017. Evaluation of Eight Current Reanalyses in Simulating Land Surface Temperature from 1979 to 2003 in China. Journal of Climate, 30: 7379-7398. https://doi.org/10.1175/jcli-d-16-0903.1.

Zhu Z, Shi C, Zhang T, Chen Z, Meng X. 2015. Applicability analysis of various reanalyzed land surface temperature datasets in China. Journal of Glaciology \& Geocryology, 37: 614-624. 
721 Table LIST

722

Table 1. Atmospheric reanalysis datasets applied in this study

\begin{tabular}{|c|c|c|c|c|c|c|}
\hline Dataset & Institution & $\begin{array}{l}\text { Model } \\
\text { resolution }\end{array}$ & $\begin{array}{l}\text { Assimilation } \\
\text { system }\end{array}$ & Period & $\begin{array}{l}\text { Assimilated } \\
\text { and } \\
\text { analysed } \\
\text { SAT }\end{array}$ & Reference \\
\hline NCEPV1 & NCEP/NCAR & $\begin{array}{l}\text { T62-210 km, } \\
28 \mathrm{~L}\end{array}$ & 3D-Var & $1948-$ & No & $\begin{array}{l}\text { Kalnay et } \\
\text { al. (1996) }\end{array}$ \\
\hline NCEPV2 & NCEP/DOE & $\begin{array}{l}\mathrm{T} 62-210 \mathrm{~km}, \\
28 \mathrm{~L}\end{array}$ & 3D-Var & $1979-$ & No & \begin{tabular}{ll}
\multicolumn{2}{l}{ Kanamitsu } \\
et & al. \\
$(\mathbf{2 0 0 2})$ &
\end{tabular} \\
\hline ERA5 & ECMWF & $\begin{array}{l}\mathrm{T} 225-80 \mathrm{~km}, \\
137 \mathrm{~L}\end{array}$ & 4D-Var & $1979-$ & Yes & \begin{tabular}{l}
\multicolumn{2}{l}{ Hersbach } \\
et al. \\
$(\mathbf{2 0 2 0})$
\end{tabular} \\
\hline CFSR & NCEP & $\begin{array}{l}\text { T382-38 km, } \\
64 \mathrm{~L}\end{array}$ & 3D-Var & $1979-$ & No & $\begin{array}{l}\text { Saha et al. } \\
(2010)\end{array}$ \\
\hline MERRA & NASA/GMAO & $\begin{array}{l}0.5 \times 0.667-55 \\
\mathrm{~km}, 72 \mathrm{~L}\end{array}$ & 3D-Var & $1979-$ & No & \begin{tabular}{l}
\multicolumn{2}{l}{ Rienecker } \\
et $\quad$ al. \\
$(\mathbf{2 0 1 1})$
\end{tabular} \\
\hline JRA55 & JMA & $\begin{array}{l}\text { T319-210 km, } \\
60 \mathrm{~L}\end{array}$ & 4D-Var & $1958-$ & Yes & \begin{tabular}{l}
\multicolumn{2}{l}{ Kobayashi } \\
et $\quad$ al. \\
$(\mathbf{2 0 1 5 )}$
\end{tabular} \\
\hline $20 \mathrm{CRV} 3$ & $\begin{array}{l}\text { NOAA- } \\
\text { CIRES-DOE }\end{array}$ & $\begin{array}{l}\mathrm{T} 225-80 \mathrm{~km}, \\
60 \mathrm{~L}\end{array}$ & $\begin{array}{l}\text { Ensemble } \\
\text { Kalman } \\
\text { filter }\end{array}$ & $1836-$ & No & $\begin{array}{l}\text { Slivinski et } \\
\text { al. (2019) }\end{array}$ \\
\hline CRA40 & CMA & $\begin{array}{l}\text { T574-55 km, } \\
64 \mathrm{~L}\end{array}$ & 3D-Var & $1979-$ & No & $\begin{array}{l}\text { Liang et al. } \\
(2020)\end{array}$ \\
\hline
\end{tabular}


Table 2. Relative bias between the REAs and OBS for climate state and linear trends for the periods $1961-2015$ and $1979-2015$

\begin{tabular}{lllll}
\hline \multirow{2}{*}{ Period } & $1961-2015$ & \multicolumn{3}{c}{ 1979-2015 } \\
\cline { 2 - 5 } & T bias & Trend bias & T bias & Trend bias \\
\hline NCEPV1 & $-12.3 \%$ & $4.0 \%$ & $-12.1 \%$ & $-9.2 \%$ \\
JRA55 & $-5.6 \%$ & $10.5 \%$ & $-5.4 \%$ & $12 \%$ \\
20CRV3 & $-5.1 \%$ & $-11.0 \%$ & $-5.3 \%$ & $6.3 \%$ \\
CRA40 & - & - & $-0.3 \%$ & $7.0 \%$ \\
ERA5 & - & - & $-2.3 \%$ & $13.8 \%$ \\
CFSR & - & - & $-11.8 \%$ & $8.8 \%$ \\
MERRA & - & - & $-0.8 \%$ & $-26.2 \%$ \\
NCEPV2 & - & - & $-13.5 \%$ & $-30.5 \%$ \\
\hline
\end{tabular}


Table 3. Standard deviation ratio (SDR) and correlation coefficient (R) of annual mean SAT across China derived from REAs and OBS for the periods 1961-2015 and 1979-2015 (thresholds for the

$73395 \%$ confidence level are 0.26 and 0.32 respectively)

\begin{tabular}{lllll}
\hline \multirow{2}{*}{ Period } & \multicolumn{1}{l}{$1961-2015$} & & $1979-2015$ & \\
\cline { 2 - 5 } & $\mathrm{R}$ & $\mathrm{SDR}$ & $\mathrm{R}$ & $\mathrm{SDR}$ \\
\hline NCEPV1 & 0.962 & 1.057 & 0.986 & 1.006 \\
JRA55 & 0.993 & 1.067 & 0.996 & 1.064 \\
20CRV3 & 0.935 & 1.034 & 0.948 & 1.133 \\
CRA40 & - & - & 0.991 & 1.086 \\
ERA5 & - & - & 0.997 & 1.087 \\
CFSR & - & - & 0.951 & 1.186 \\
MERRA & - & - & 0.959 & 0.868 \\
NCEPV2 & - & - & 0.952 & 1.058 \\
\hline
\end{tabular}


Table 4. R and SDR values between the REAs and OBS at different elevations for the periods $738 \quad 1961-2015$ and 1979-2015

\begin{tabular}{|c|c|c|c|c|c|c|c|c|c|}
\hline \multirow{2}{*}{ Period } & \multirow{2}{*}{ Data } & \multicolumn{2}{|c|}{$0-500 \mathrm{~m}$} & \multicolumn{2}{|c|}{$500-1500 \mathrm{~m}$} & \multicolumn{2}{|c|}{$1500-3000 \mathrm{~m}$} & \multicolumn{2}{|c|}{$3000-5000 \mathrm{~m}$} \\
\hline & & $\mathrm{R}$ & SDR & $\mathrm{R}$ & SDR & $\mathrm{R}$ & SDR & $\mathrm{R}$ & SDR \\
\hline \multirow{8}{*}{$\begin{array}{l}1979- \\
2015\end{array}$} & NCEPV1 & 0.88 & 1.02 & 0.85 & 1.05 & 0.78 & 0.92 & 0.61 & 0.90 \\
\hline & JRA55 & 0.94 & 0.99 & 0.91 & 1.06 & 0.87 & 1.03 & 0.88 & 1.00 \\
\hline & 20CRV3 & 0.85 & 1.07 & 0.82 & 1.09 & 0.81 & 1.04 & 0.79 & 1.10 \\
\hline & CRA40 & 0.91 & 1.09 & 0.89 & 1.06 & 0.86 & 1.01 & 0.73 & 1.40 \\
\hline & NCEPV2 & 0.85 & 1.07 & 0.76 & 1.12 & 0.51 & 1.11 & 0.26 & 1.31 \\
\hline & ERA5 & 0.93 & 1.02 & 0.91 & 1.09 & 0.85 & 1.14 & 0.70 & 1.32 \\
\hline & CFSR & 0.85 & 1.23 & 0.74 & 1.22 & 0.66 & 1.22 & 0.43 & 1.75 \\
\hline & MERRA & 0.84 & 0.98 & 0.77 & 0.94 & 0.63 & 0.87 & 0.79 & 0.93 \\
\hline \multirow{3}{*}{$\begin{array}{l}1961- \\
2015\end{array}$} & NCEPV1 & 0.79 & 1.23 & 0.75 & 1.11 & 0.65 & 0.95 & 0.48 & 0.90 \\
\hline & JRA55 & 0.92 & 1.00 & 0.89 & 1.07 & 0.85 & 1.08 & 0.86 & 1.06 \\
\hline & 20CRV3 & 0.58 & 1.02 & 0.60 & 1.06 & 0.65 & 0.97 & 0.59 & 0.96 \\
\hline
\end{tabular}


742 Table 5. Ranking and score of each of the reanalysis datasets in mainland China for the periods

$743 \quad 1961-2015$ and 1979-2015

\begin{tabular}{|c|c|c|c|c|c|c|}
\hline Period & $\begin{array}{l}\text { Dataset } \\
\text { ranking }\end{array}$ & $\begin{array}{l}\text { Inter-annual } \\
\text { variability } \\
\text { (score) }\end{array}$ & $\begin{array}{l}\text { Dispersion } \\
\text { (score) }\end{array}$ & $\begin{array}{l}\text { Climate } \\
\text { state } \\
\text { (score) }\end{array}$ & $\begin{array}{l}\text { Linear } \\
\text { trend } \\
\text { (score) }\end{array}$ & $\begin{array}{l}\text { Integrated } \\
\text { score }\end{array}$ \\
\hline \multirow{8}{*}{$\begin{array}{r}1979 \\
-2015\end{array}$} & 1 & $\begin{array}{l}\text { ERA5 } \\
(99.7)\end{array}$ & $\begin{array}{l}\text { NCEPV1 } \\
(99.4)\end{array}$ & $\begin{array}{l}\text { CRA40 } \\
(99.7)\end{array}$ & $\begin{array}{l}\text { 20CRV3 } \\
(93.7)\end{array}$ & $\begin{array}{l}\text { CRA40 } \\
(95.8)\end{array}$ \\
\hline & 2 & $\begin{array}{l}\text { JRA55 } \\
(99.6)\end{array}$ & $\begin{array}{l}\text { NCEPV2 } \\
(94.2)\end{array}$ & $\begin{array}{l}\text { MERRA } \\
(99.2)\end{array}$ & $\begin{array}{l}\text { CRA40 } \\
(93.0)\end{array}$ & $\begin{array}{l}\text { NCEPV1 } \\
(94.2)\end{array}$ \\
\hline & 3 & $\begin{array}{l}\text { CRA40 } \\
(99.1)\end{array}$ & $\begin{array}{l}\text { JRA55 } \\
(93.6)\end{array}$ & $\begin{array}{l}\text { ERA5 } \\
(97.7)\end{array}$ & $\begin{array}{l}\text { CFSR } \\
(91.2)\end{array}$ & $\begin{array}{l}\text { ERA55 } \\
(93.7)\end{array}$ \\
\hline & 4 & $\begin{array}{l}\text { NCEPV1 } \\
(98.6)\end{array}$ & $\begin{array}{l}\text { CRA40 } \\
(91.4)\end{array}$ & $\begin{array}{l}\text { JRA55 } \\
(94.6)\end{array}$ & $\begin{array}{l}\text { NCEPV1 } \\
(90.8)\end{array}$ & $\begin{array}{l}\text { JRA5 } \\
(93.5)\end{array}$ \\
\hline & 5 & $\begin{array}{l}\text { MERRA } \\
(95.9)\end{array}$ & $\begin{array}{l}\text { ERA5 } \\
(91.3)\end{array}$ & $\begin{array}{l}\text { 20CRV3 } \\
(94.6)\end{array}$ & $\begin{array}{l}\text { JRA55 } \\
(88.0)\end{array}$ & $\begin{array}{l}\text { 20CRV3 } \\
(92.5)\end{array}$ \\
\hline & 6 & $\begin{array}{l}\text { NCEPV2 } \\
(95.2)\end{array}$ & $\begin{array}{l}\text { 20CRV3 } \\
(86.7)\end{array}$ & $\begin{array}{l}\text { CFSR } \\
(88.2)\end{array}$ & $\begin{array}{l}\text { ERA5 } \\
(86.2)\end{array}$ & $\begin{array}{l}\text { CFSR } \\
(89.0)\end{array}$ \\
\hline & 7 & $\begin{array}{l}\text { CFSR } \\
(95.1)\end{array}$ & $\begin{array}{l}\text { MERRA } \\
(86.8)\end{array}$ & $\begin{array}{l}\text { NCEPV1 } \\
(87.9)\end{array}$ & $\begin{array}{l}\text { MERRA } \\
\text { (73.8) }\end{array}$ & $\begin{array}{l}\text { MERRA } \\
(88.9)\end{array}$ \\
\hline & 8 & $\begin{array}{l}\text { 20CRV3 } \\
(94.8)\end{array}$ & $\begin{array}{l}\text { CFSR } \\
(81.4)\end{array}$ & $\begin{array}{l}\text { NCEPV2 } \\
(86.5)\end{array}$ & $\begin{array}{l}\text { NCEPV2 } \\
(69.5)\end{array}$ & $\begin{array}{l}\text { NCEPV2 } \\
(86.4)\end{array}$ \\
\hline \multirow{3}{*}{$\begin{array}{l}1961- \\
2015\end{array}$} & 1 & $\begin{array}{l}\text { JRA55 } \\
(99.3)\end{array}$ & $\begin{array}{l}\text { 20CRV3 } \\
(96.6)\end{array}$ & $\begin{array}{l}\text { 20CRV3 } \\
(94.9)\end{array}$ & $\begin{array}{l}\text { NCEPV1 } \\
(95.8)\end{array}$ & $\begin{array}{l}\text { JRA55 } \\
(94.1)\end{array}$ \\
\hline & 2 & $\begin{array}{l}\text { NCEPV1 } \\
(96.2)\end{array}$ & $\begin{array}{l}\text { NCEPV1 } \\
(94.3)\end{array}$ & $\begin{array}{l}\text { JRA55 } \\
(94.4)\end{array}$ & $\begin{array}{l}\text { JRA55 } \\
(89.5)\end{array}$ & $\begin{array}{l}\text { 20CRV3 } \\
(93.5)\end{array}$ \\
\hline & 3 & $\begin{array}{l}\text { 20CRV3 } \\
(93.5)\end{array}$ & $\begin{array}{l}\text { JRA55 } \\
(93.3)\end{array}$ & $\begin{array}{l}\text { NCEPV1 } \\
(87.7)\end{array}$ & $\begin{array}{l}\text { 20CRV3 } \\
(89.0)\end{array}$ & $\begin{array}{l}\text { NCEPV1 } \\
(93.5)\end{array}$ \\
\hline
\end{tabular}



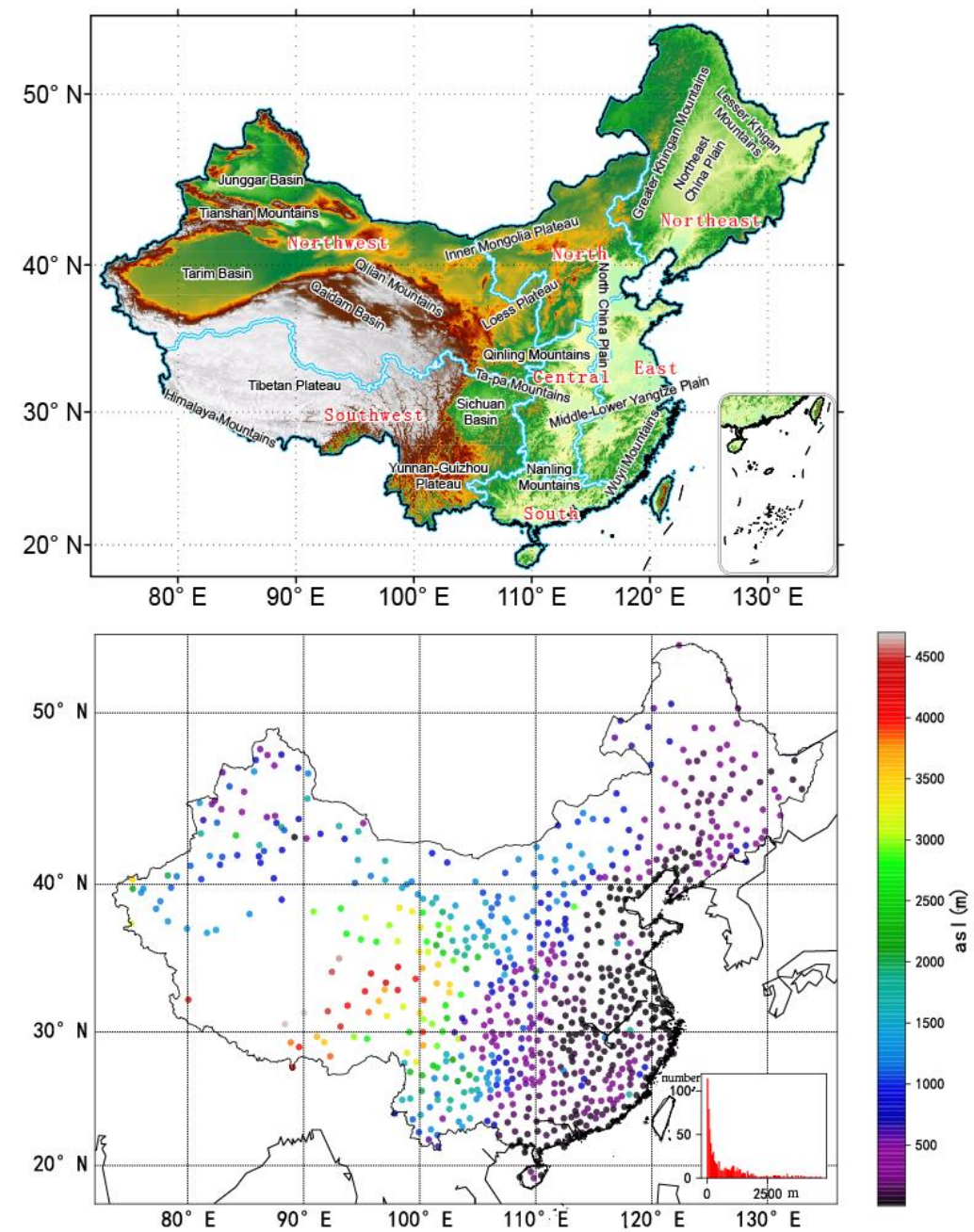

Figure 1. Distribution of the elevation distribution and 763 observation stations across mainland China. (The insert shows the number of stations at various elevations, the asl stands for elevation (units: $\mathrm{m}$ ), the red bar stands for the number of the elevation distribution) 

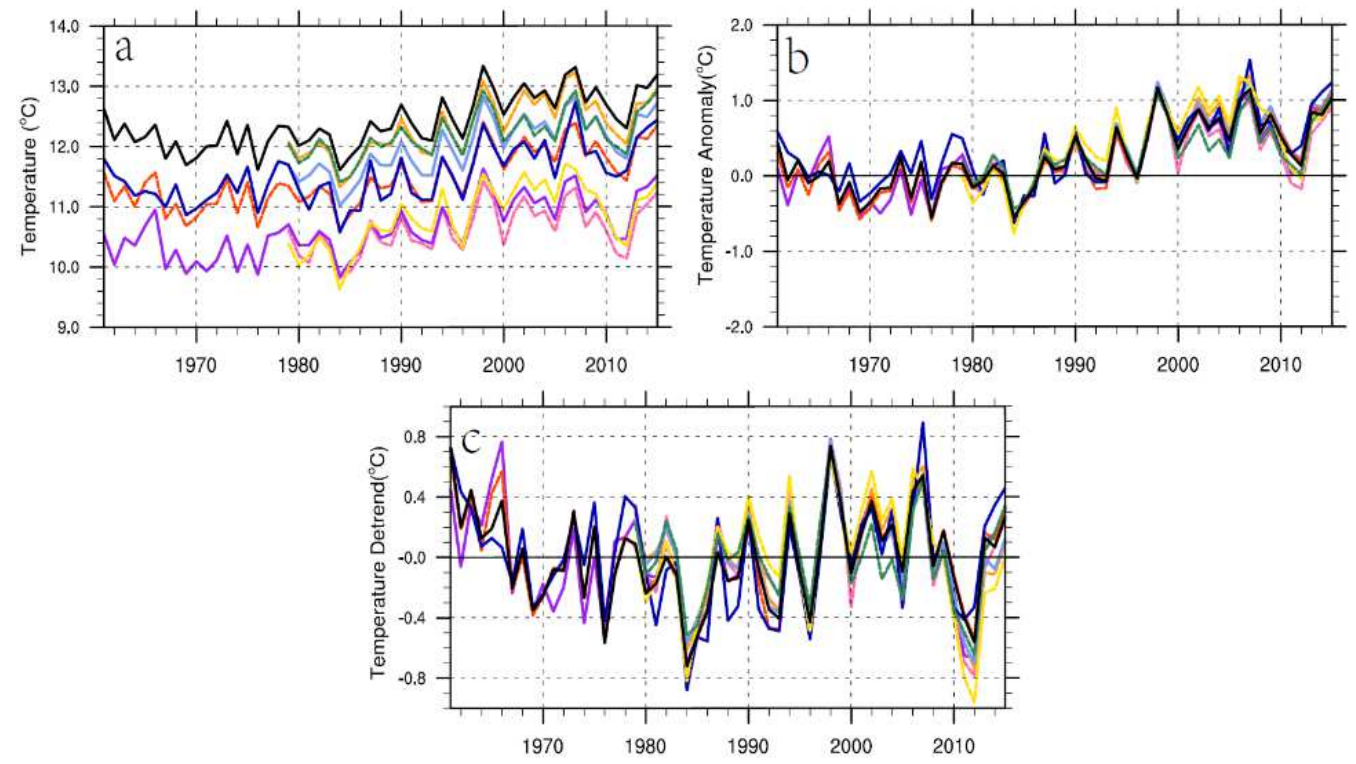

Figure 2. Time series of annual mean SAT across mainland China from 1961-2015 derived from OBS and REAs: (a)SAT; (b) SAT anomalies; (c) SAT with linear trends removed. (units: ${ }^{\circ} \mathrm{C}$ ) 

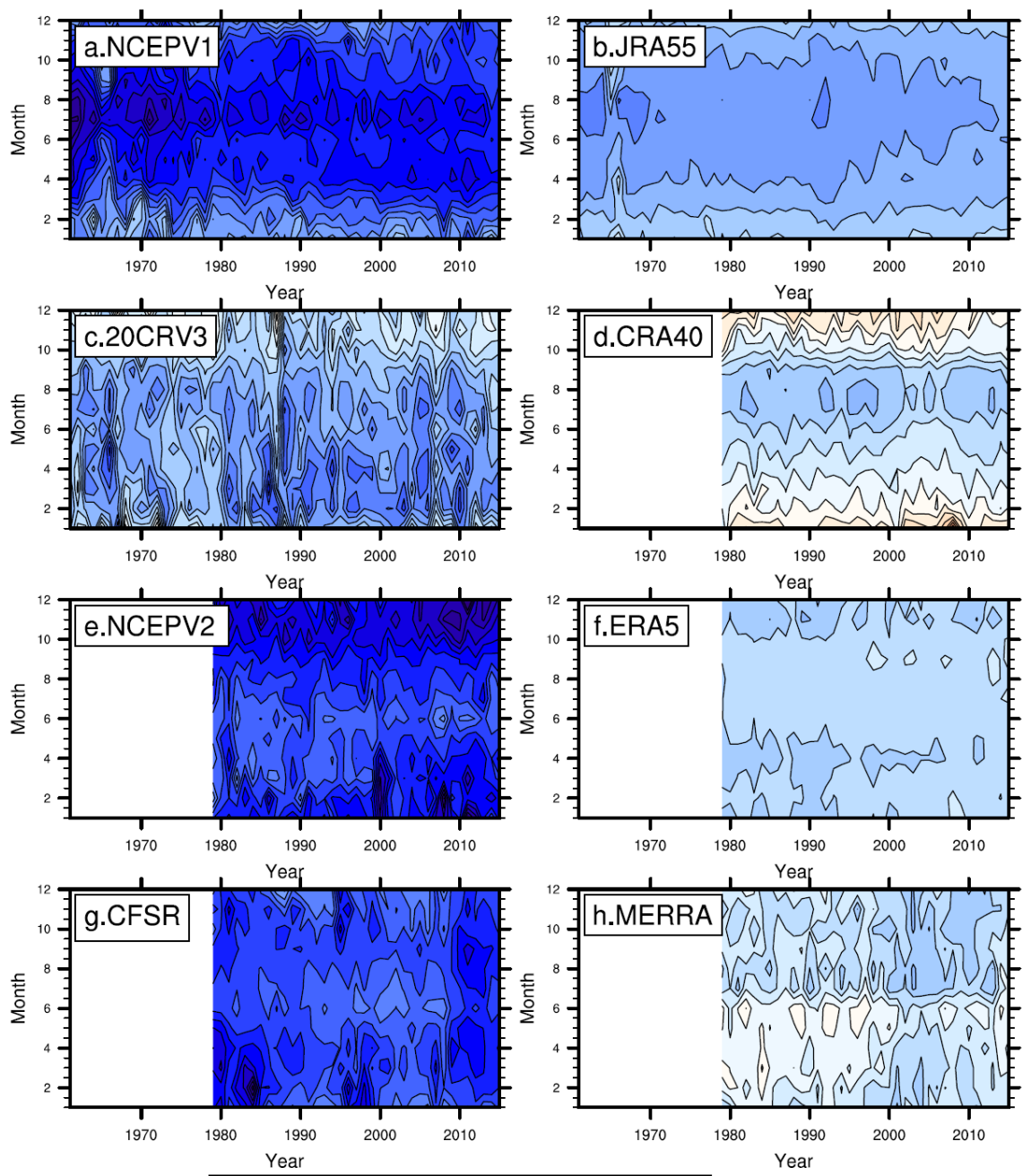

758 Figure 3. The bias of monthly mean SAT between REAs and OBS from 1961-2015 across mainland China: (a) NCEPV1; (b) JRA55; (c) 20CRV3; (d) CRA40; (e) NCEPV2; (f) ERA5; (g) CFSR; (h) MERRA. (The value of color bar means the monthly mean SAT bias (units: ${ }^{\circ} \mathrm{C}$ )) 

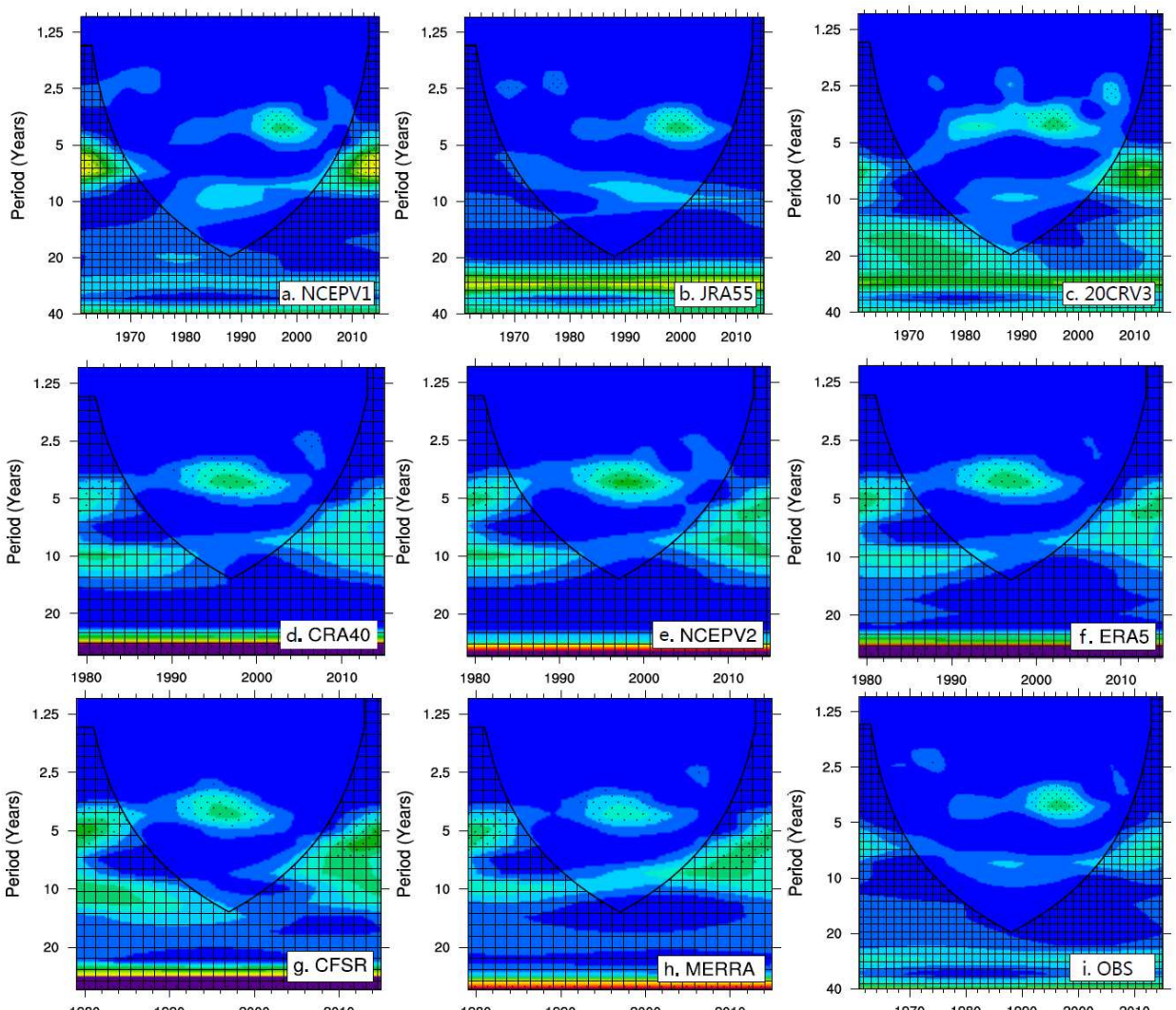

763 Figure 4. Wavelet analysis based on REAs and OBS from 1961-2015: (a) NCEPV1; (b) JRA55; (c) 20CRV3; (d) CRA40; (e) NCEPV2; (f) ERA5; (g) CFSR ; (h) MERRA ; (i) OBS. 

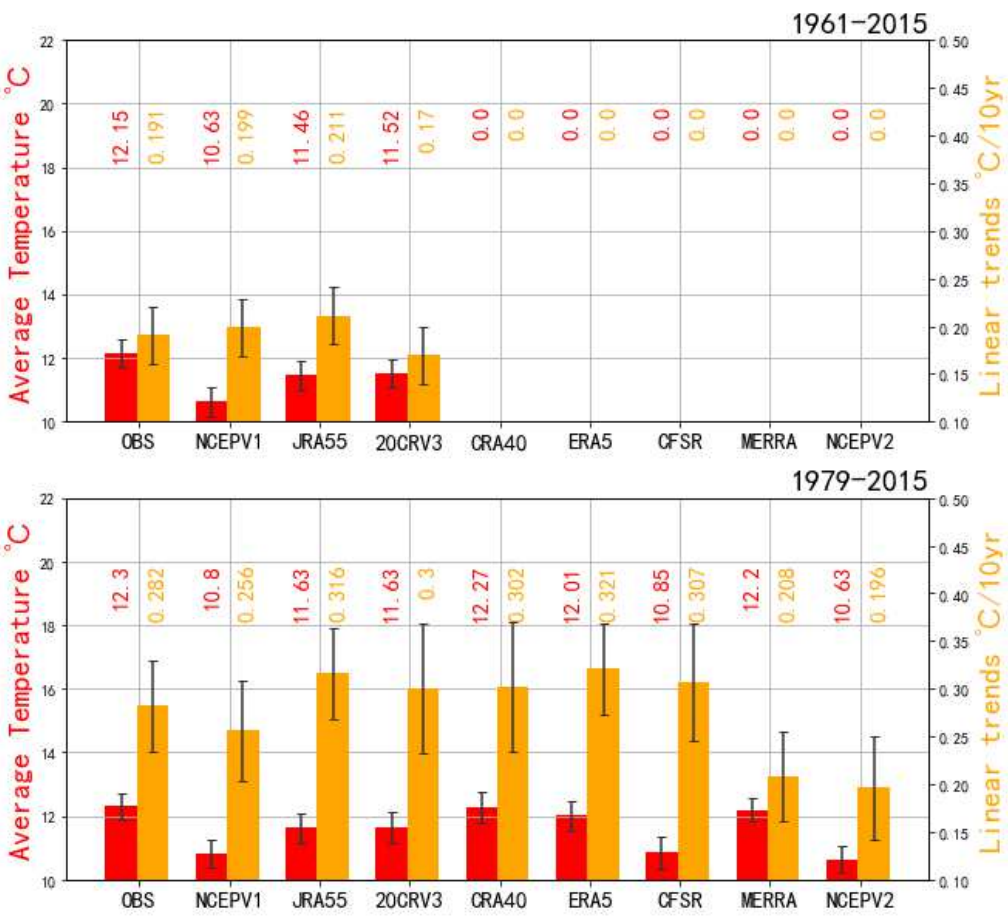

Figure 5. Annual mean SAT and annual mean SAT linear trends for the periods 1961-2015 and 1979-2015. (The red bar stand for climate state (units: ${ }^{\circ} \mathrm{C}$ ), the orange bar stands for linear trends 770 (units: ${ }^{\circ} \mathrm{C} / 10$ years))

771 


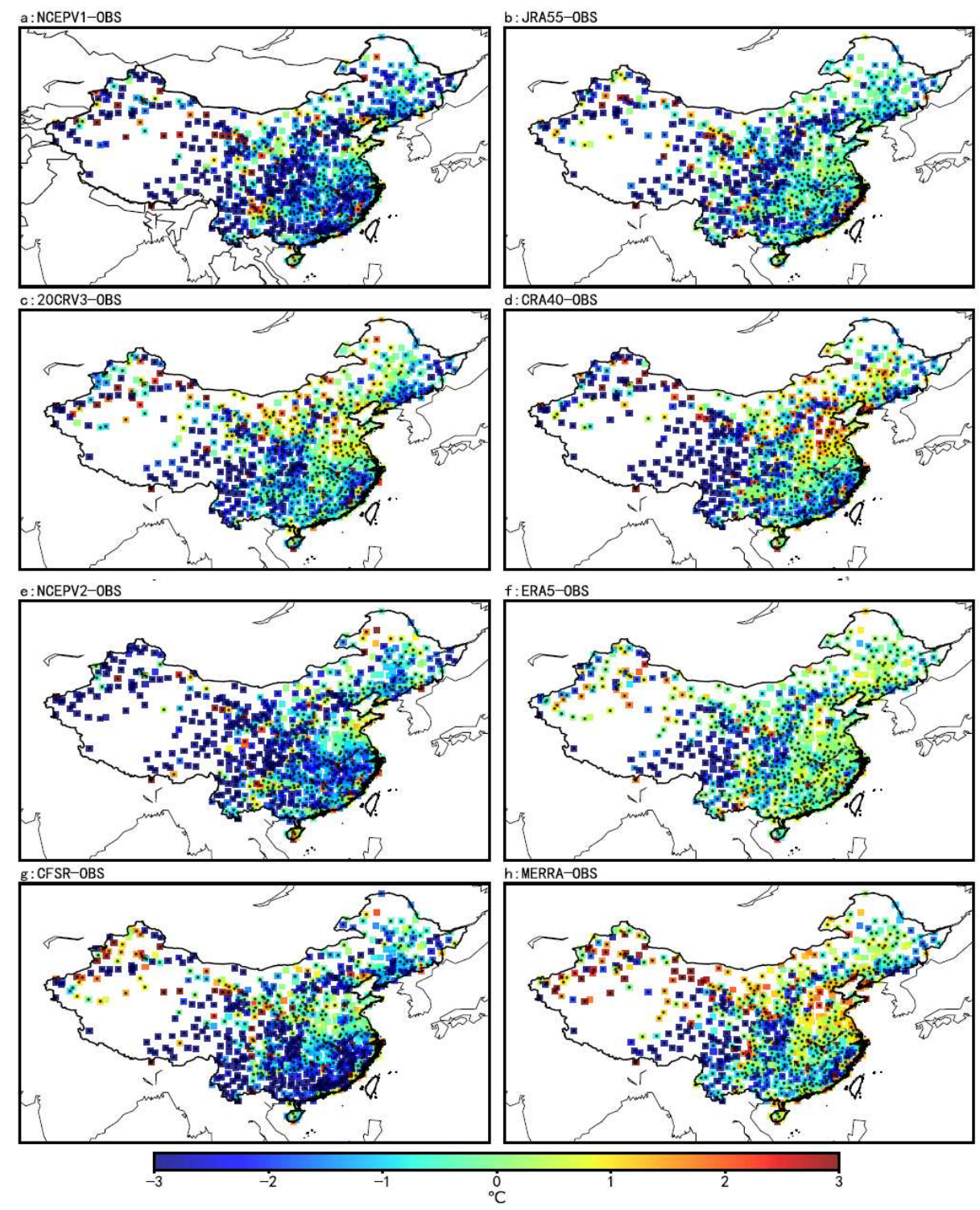

772

Figure 6. Spatial distribution of annual mean SAT bias of REAs from observations for the period

774 1979-2015 across mainland China:(a)NCEPV1; (b) JRA55; (c) 20CRV3; (d) CRA40; (e) NCEPV2;

775 (f) ERA5; (g) CFSR; (h) MERRA

776 (The black dots represent significant deviation, the value of color bar means the annual mean SAT

777 bias (units: $\left.{ }^{\circ} \mathrm{C}\right)$ ) 

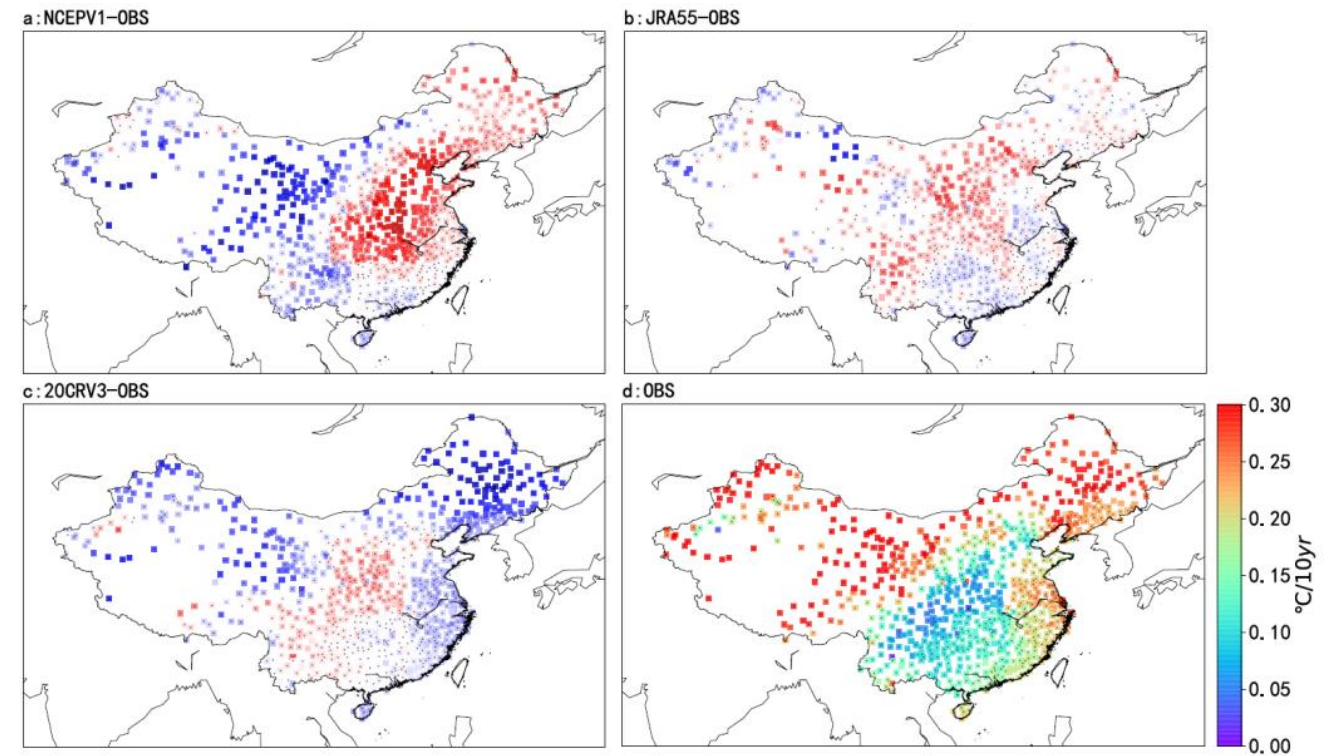

$-0.2$

Figure 7. Spatial distribution of linear trend of OBS and linear trend bias between REA and OBS for the period 1961-2015 across China:(a)NCEPV1; (b) JRA55; (c) 20CRV3 (d) OBS. (The black dots represent significant deviation, the value of color bar means the linear trend bias and linear trend (units: ${ }^{\circ} \mathrm{C} / 10$ year)) 

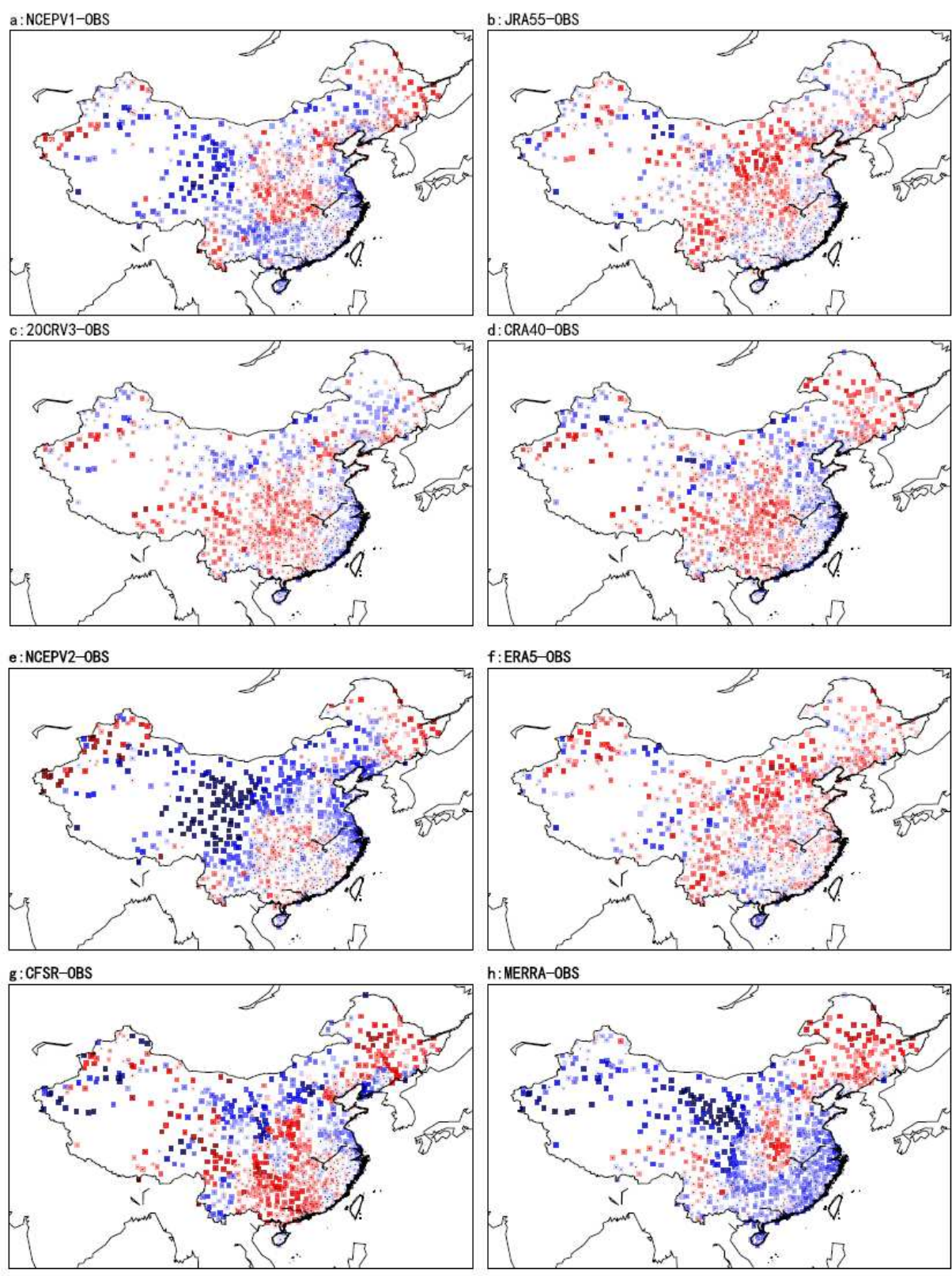

$h:$ MERRA-OBS

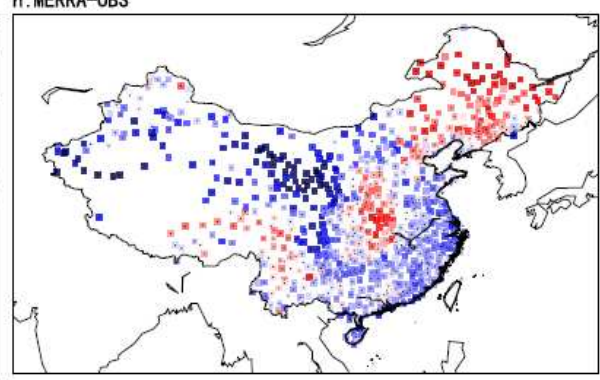

Figure 8. Spatial distribution of linear trend bias between REA and OBS for the period 1979-2015 across China:(a) NCEPV1; (b) JRA55; (c) 20CRV3; (d) CRA40; (e) NCEPV2; (f) ERA5; (g) CFSR; (h) MERRA.(The black dots represent significant deviation, the value of color bar means the linear trend bias (units: ${ }^{\circ} \mathrm{C} / 10$ year)) 

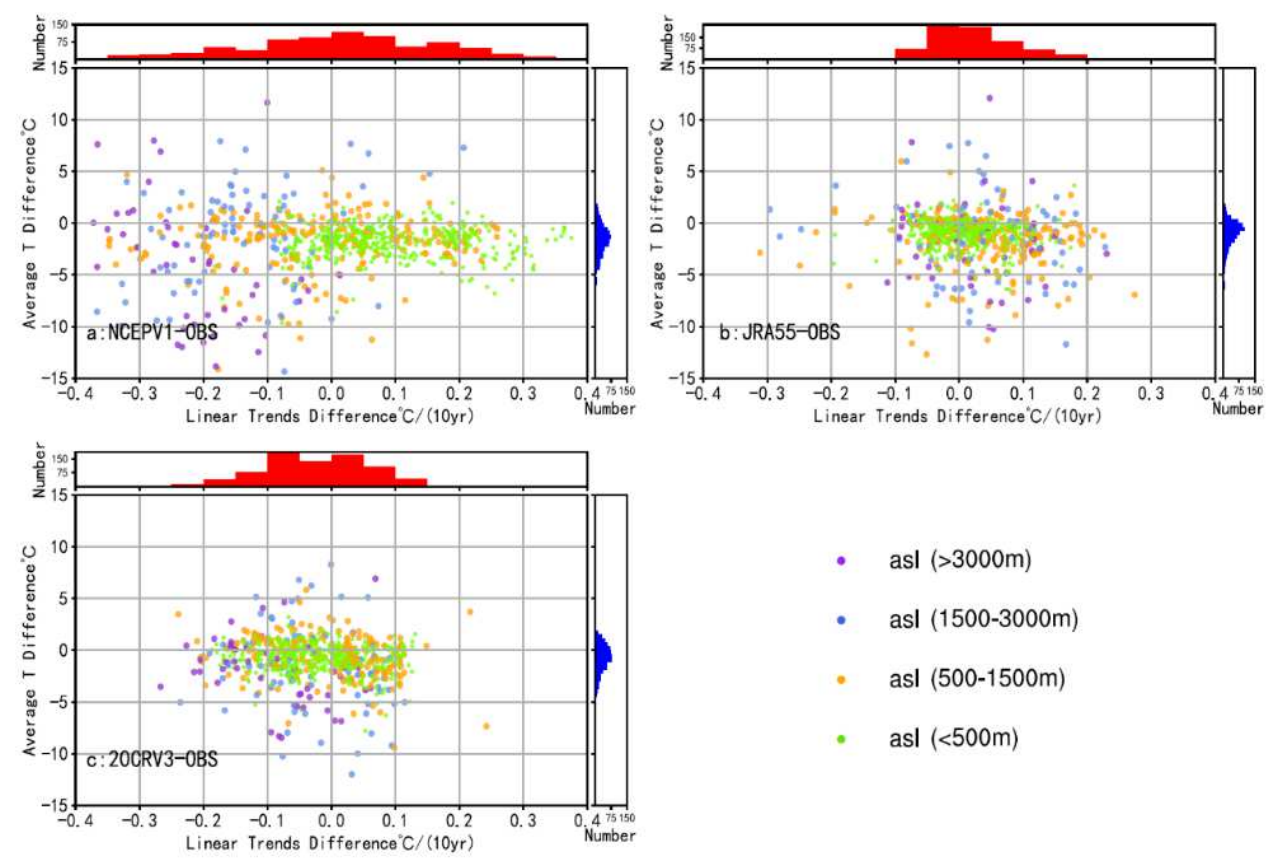

Figure 9. The biases of climate state and linear trends of annual mean temperature between REAs and OBS for the period 1961-2015. (a) NCEPV1;

(b) JRA55; (c) 20CRV3. (The asl stands for elevation (units: $\mathrm{m}$ ); $\mathrm{y}$-axis stand for the bias of climate state (units: ${ }^{\circ} \mathrm{C}$ ); $\mathrm{x}$-axis stand for the bias of linear trends (units: ${ }^{\circ} \mathrm{C} / 10$ years); red bar stand for the number of stations with different bias of linear trends; blue bar stand for the number of stations with different bias of climate state; purple dots represent the altitude of stations above $3000 \mathrm{~m}$; blue dots represent the altitude of stations between 1500-3000m; orange dots represent the altitude of stations between $500-1500 \mathrm{~m}$; green dots represent the altitude of stations less than 500m) 

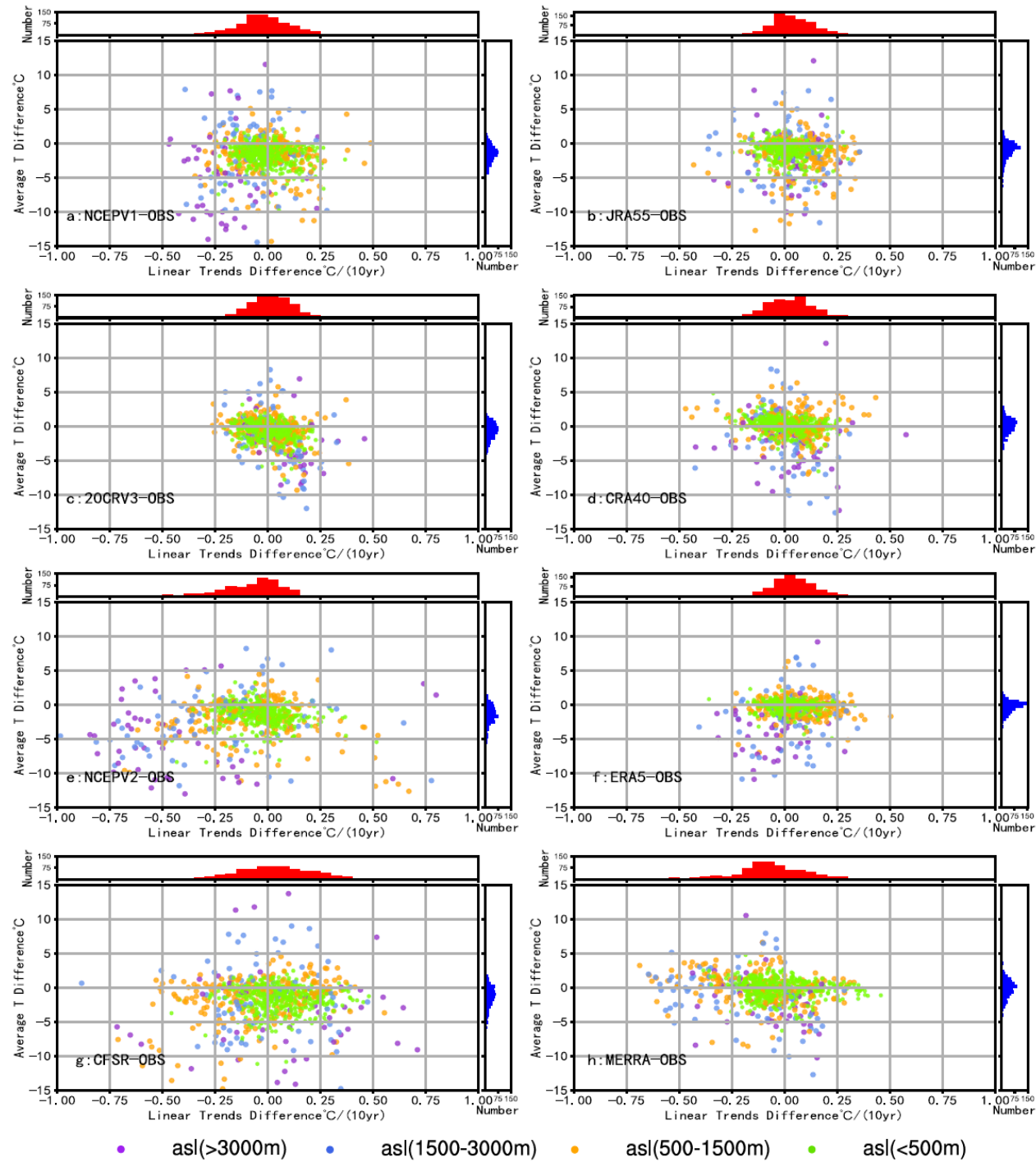

Figure 10. The biases of climate state and linear trends of annual mean temperature between the REAs and OBS for the period 1979-2015. (a) NCEPV1; (b) JRA55; (c) 20CRV3; (d) CRA40; (e) NCEPV2; (f) ERA5; (g) CFSR; (h) MERRA.

(The asl stands for elevation (units: $\mathrm{m}$ ); $\mathrm{y}$-axis stand for the bias of climate state (units: ${ }^{\circ} \mathrm{C}$ ); $\mathrm{x}$-axis stand for the bias of linear trends (units: ${ }^{\circ} \mathrm{C} / 10$ years); red bar stand for the number of stations with different bias of linear trends; blue bar stand for the number of stations with different bias of climate state; purple dots represent the altitude of stations above $3000 \mathrm{~m}$;blue dots represent the altitude of stations between $1500-3000 \mathrm{~m}$; orange dots represent the altitude of stations between $500-1500 \mathrm{~m}$; green dots represent the altitude of stations less than 500m) 


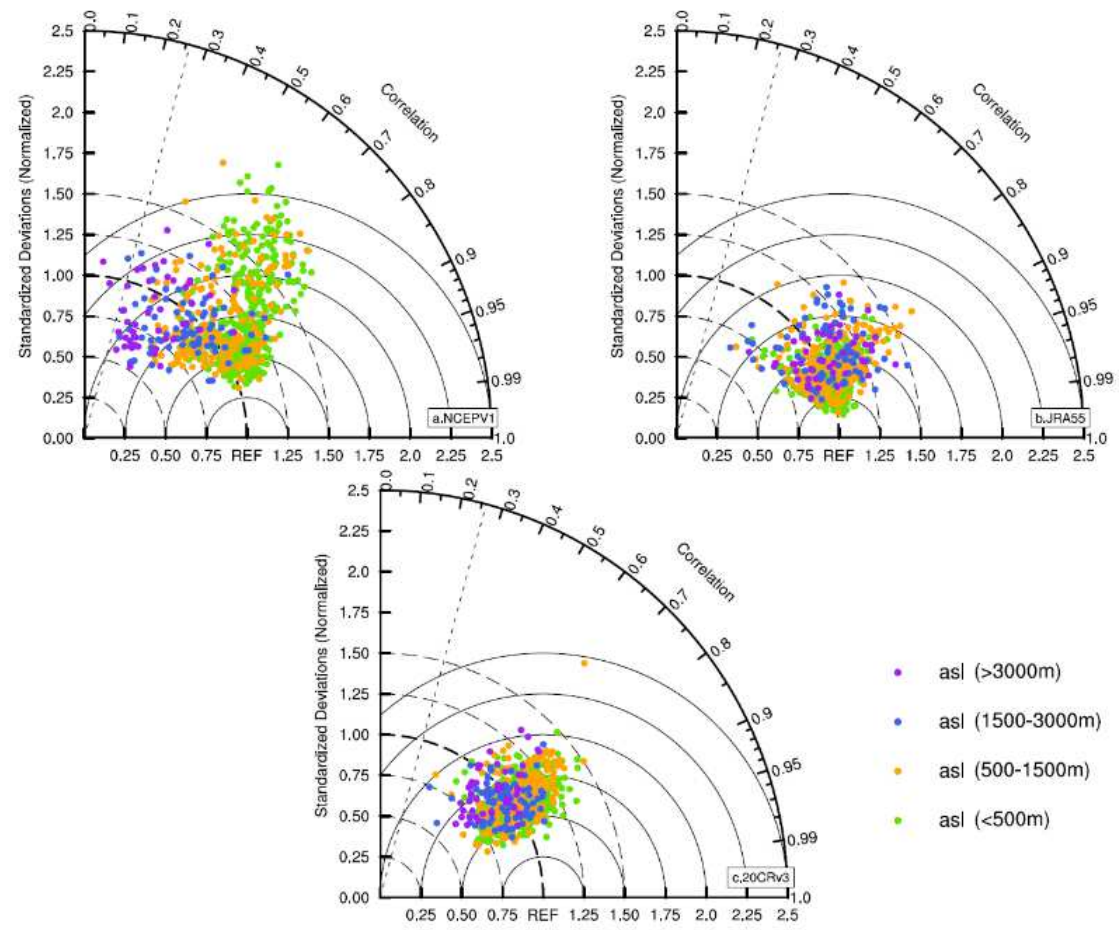

812 Figure 11. Taylor diagrams of annual mean SAT for 763 stations across mainland China derived by 813 the REAs and OBS for the period 1961-2015: (a) NCEPV1; (b) JRA55; (c) 20 CRV3.

814 (The asl stands for elevation (units: $\mathrm{m}$ ), the purple dots represent the altitude of stations above $3000 \mathrm{~m}$. The blue dots represent the altitude of stations between $1500-3000 \mathrm{~m}$. The orange dots represent the altitude of stations between $500-1500 \mathrm{~m}$. The green dots represent the altitude of stations less than $500 \mathrm{~m}$, threshold for the $95 \%$ confidence level is 0.26 ) 

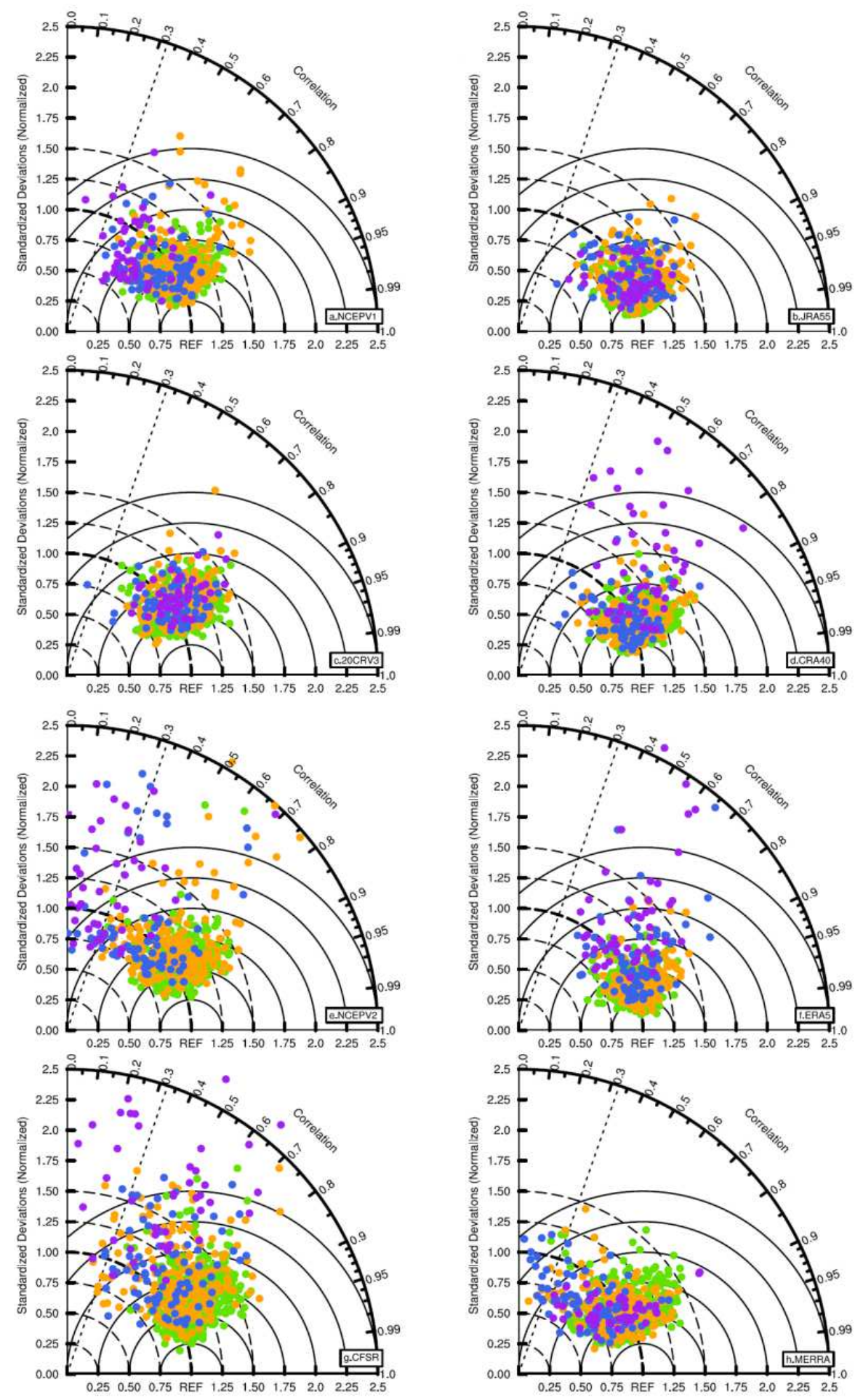

- $\quad$ asl $(>3000 \mathrm{~m})$

asl (1500-3000m)

asl $(500-1500 \mathrm{~m}) \quad$ asl $(<500 \mathrm{~m})$

Figure 12. Taylor diagrams of annual mean SAT for 763 stations across mainland China derived by the REAs and OBS for the period 1979-2015:(a) NCEPV1; (b) JRA55; (c) 20CRV3; (d) CRA40; (e) NCEPV2; (f) ERA5; (g) CFSR; (h) MERRA. (The asl stands for elevation (units: $\mathrm{m}$ ), the purple dots represent the altitude of stations above $3000 \mathrm{~m}$. The blue dots represent the altitude of stations between $1500-3000 \mathrm{~m}$. The orange dots represent the altitude of stations between $500-1500 \mathrm{~m}$. The green dots represent the altitude of stations less than $500 \mathrm{~m}$, threshold for the $95 \%$ confidence level is 0.32 ) 
Figures
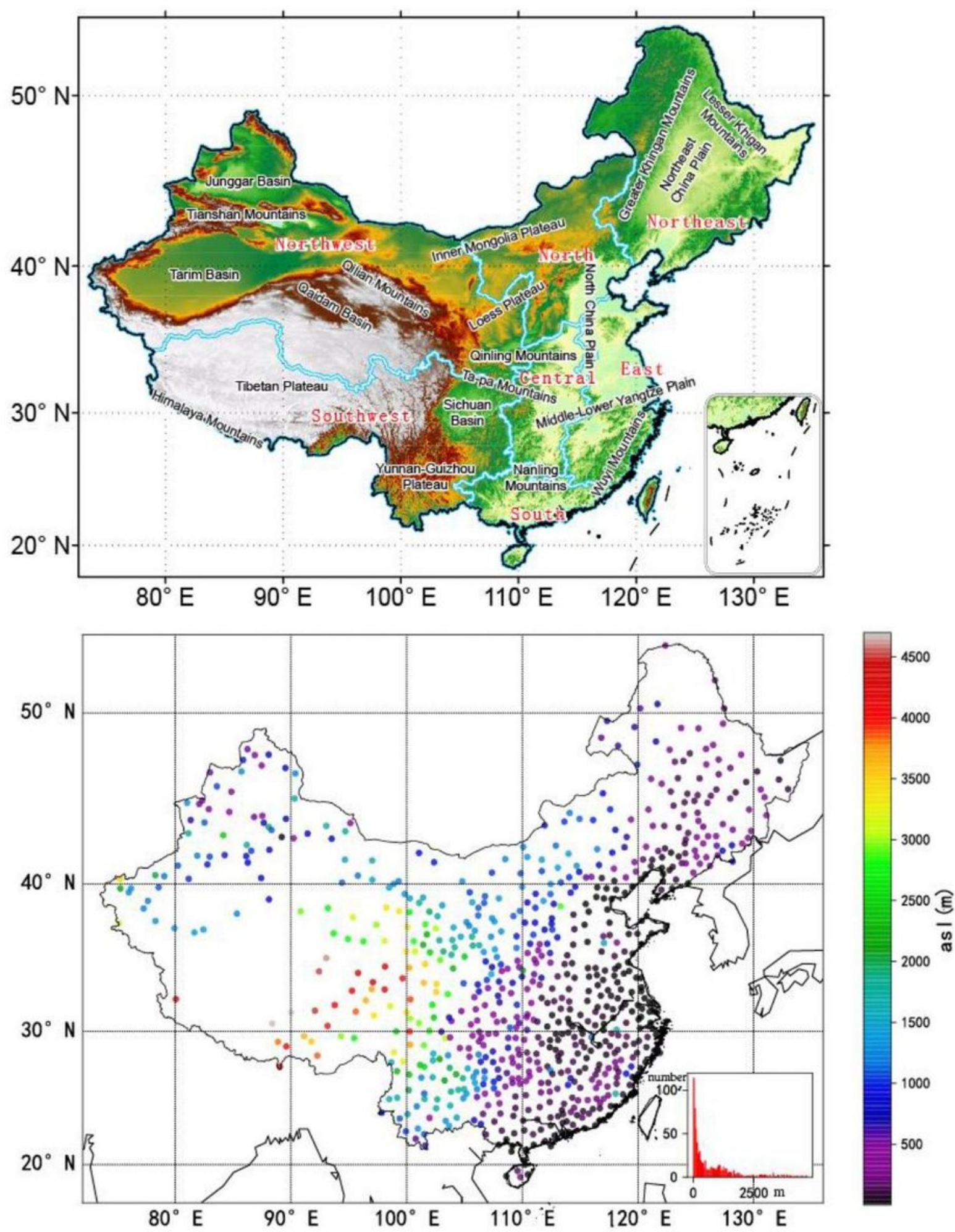

Figure 1

Distribution of the elevation distribution and 763 observation stations across mainland China. (The insert shows the number of stations at various elevations, the asl stands for elevation (units: $\mathrm{m}$ ), the red bar stands for the number of the elevation distribution) Note: The designations employed and the 
presentation of the material on this map do not imply the expression of any opinion whatsoever on the part of Research Square concerning the legal status of any country, territory, city or area or of its authorities, or concerning the delimitation of its frontiers or boundaries. This map has been provided by the authors.
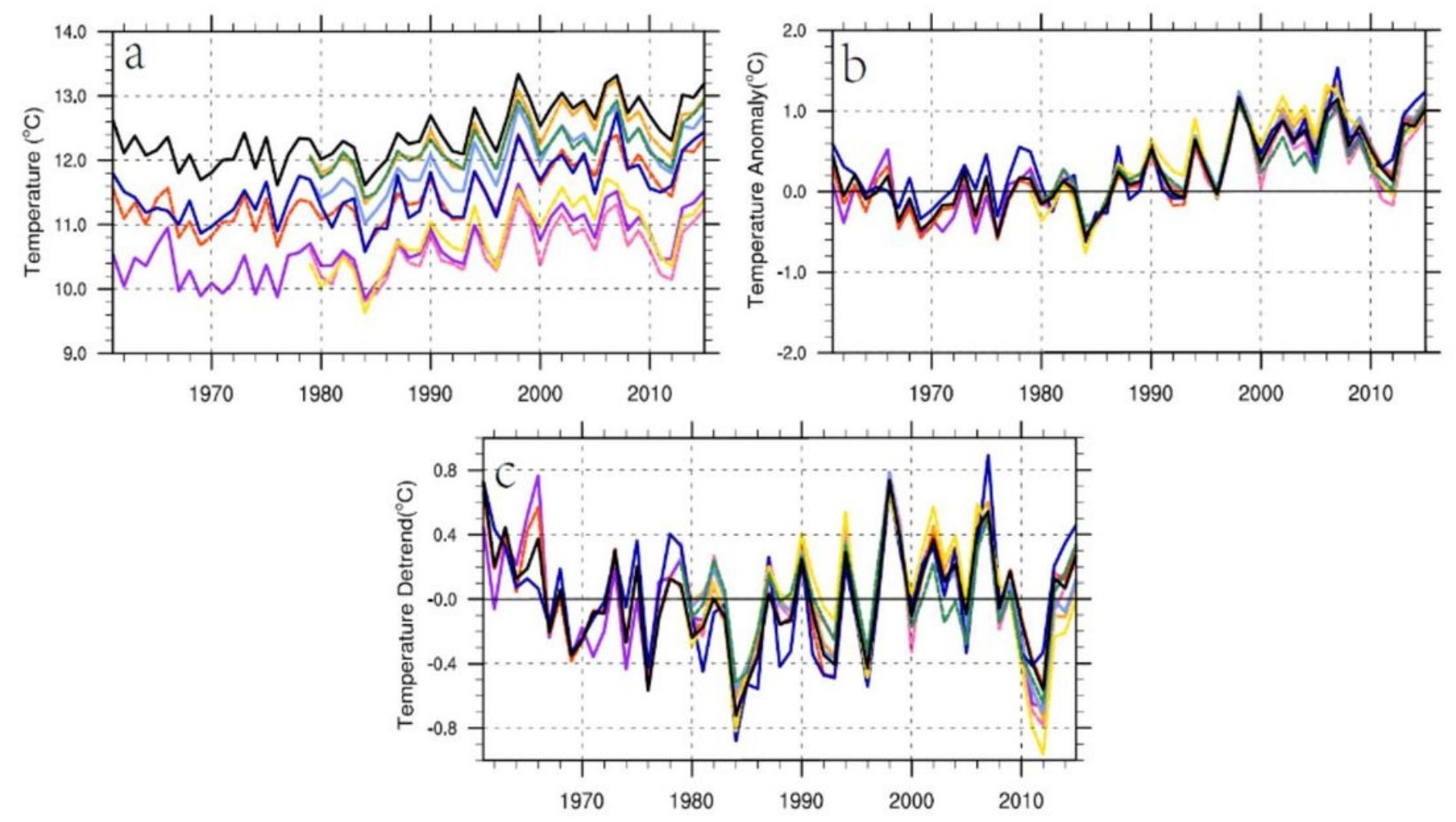

NCEPV2 - NCEPV1 - CRA40 - ERA5 -JRA55-20CRV3 - CFSR - MERRA -OBS

\section{Figure 2}

Time series of annual mean SAT across mainland China from 1961-2015 derived from OBS and REAs: (a) SAT; (b) SAT anomalies; (c) SAT with linear trends removed. (units: ${ }^{\circ} \mathrm{C}$ ) 

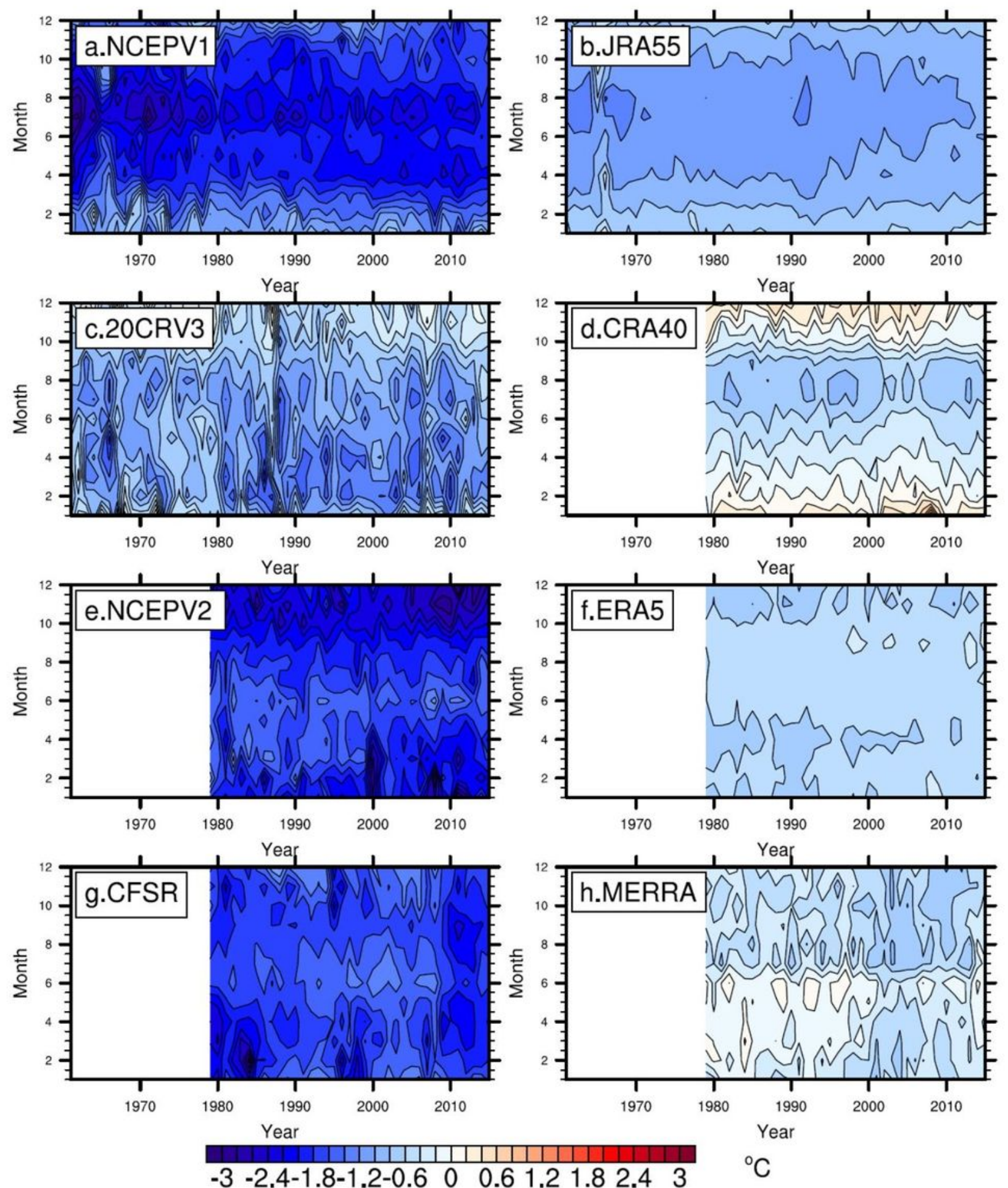

\section{Figure 3}

The bias of monthly mean SAT between REAs and OBS from 1961-2015 across mainland China: (a) NCEPV1; (b) JRA55; (c) 20CRV3; (d) CRA40; (e) NCEPV2; (f) ERA5; (g) CFSR; (h) MERRA. (The value of color bar means the monthly mean SAT bias (units: ${ }^{\circ} \mathrm{C}$ )) 

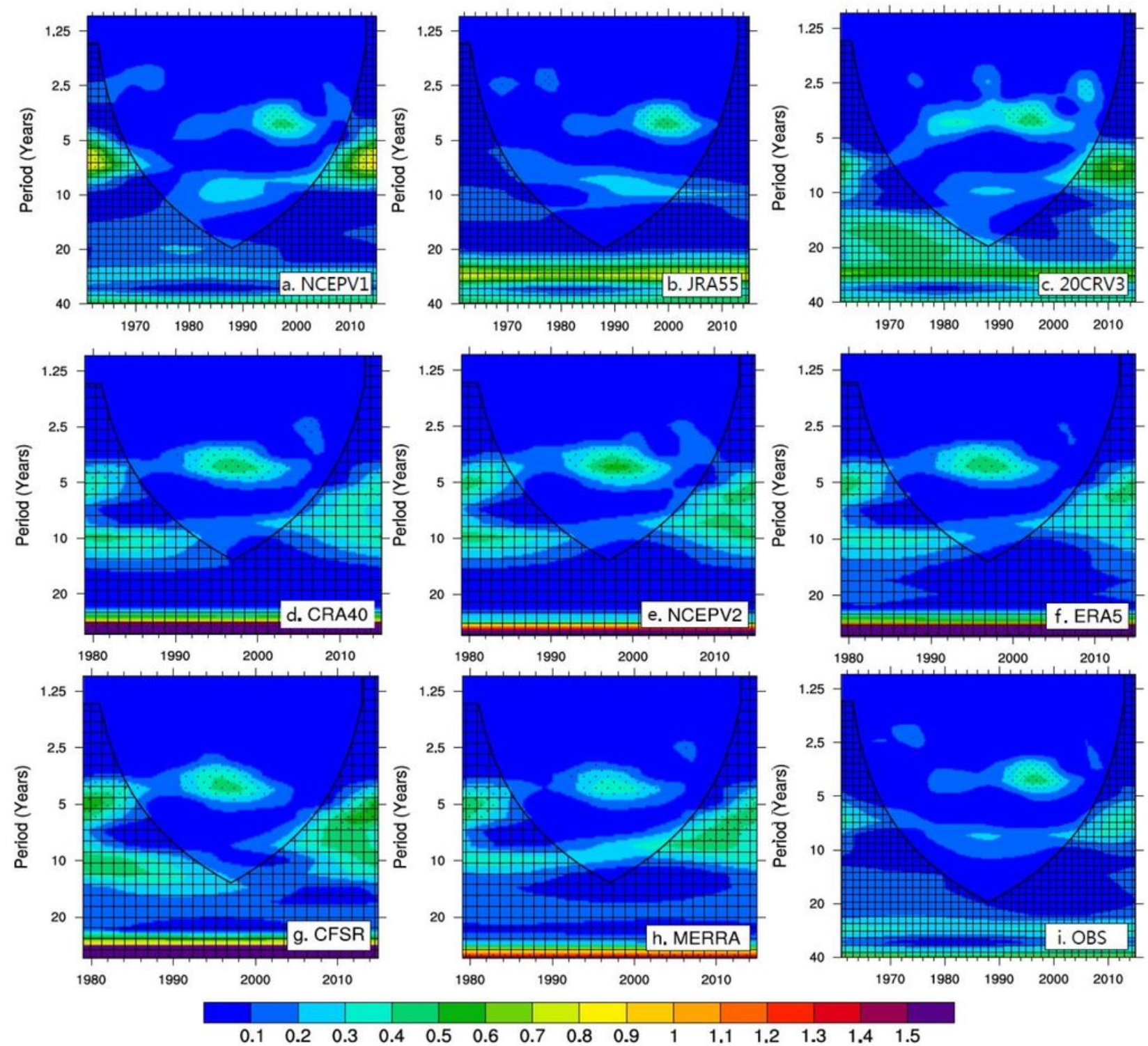

\section{Figure 4}

Wavelet analysis based on REAs and OBS from 1961-2015: (a) NCEPV1; (b) JRA55; (c) 20CRV3; (d) CRA40; (e) NCEPV2; (f) ERA5; (g) CFSR ; (h) MERRA ; (i) OBS. 

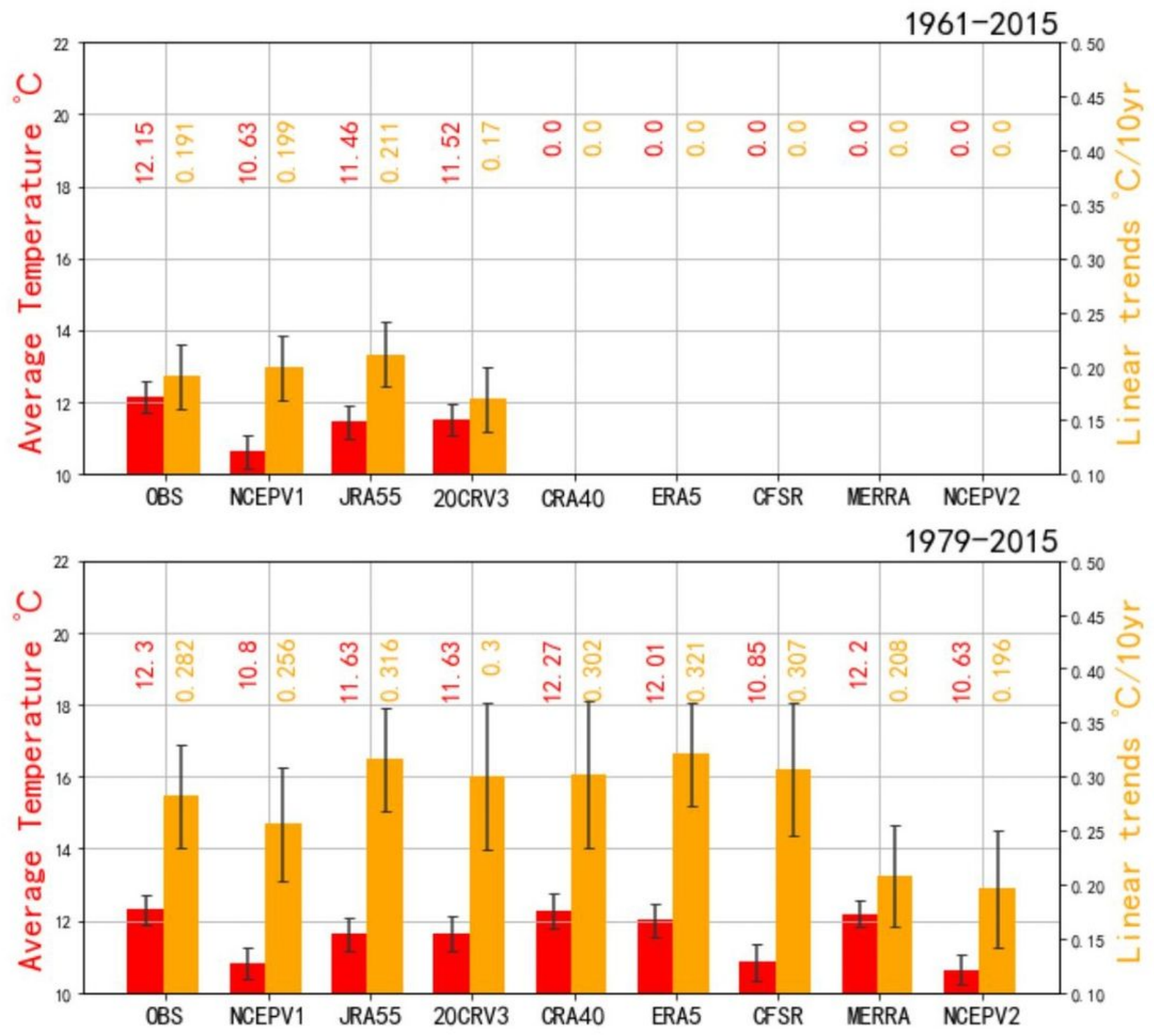

Figure 5

Annual mean SAT and annual mean SAT linear trends for the periods 1961-2015 and 1979-2015. (The red bar stand for climate state (units: ${ }^{\circ} \mathrm{C}$ ), the orange bar stand for linear trends (units: ${ }^{\circ} \mathrm{C} / 10$ years)) 

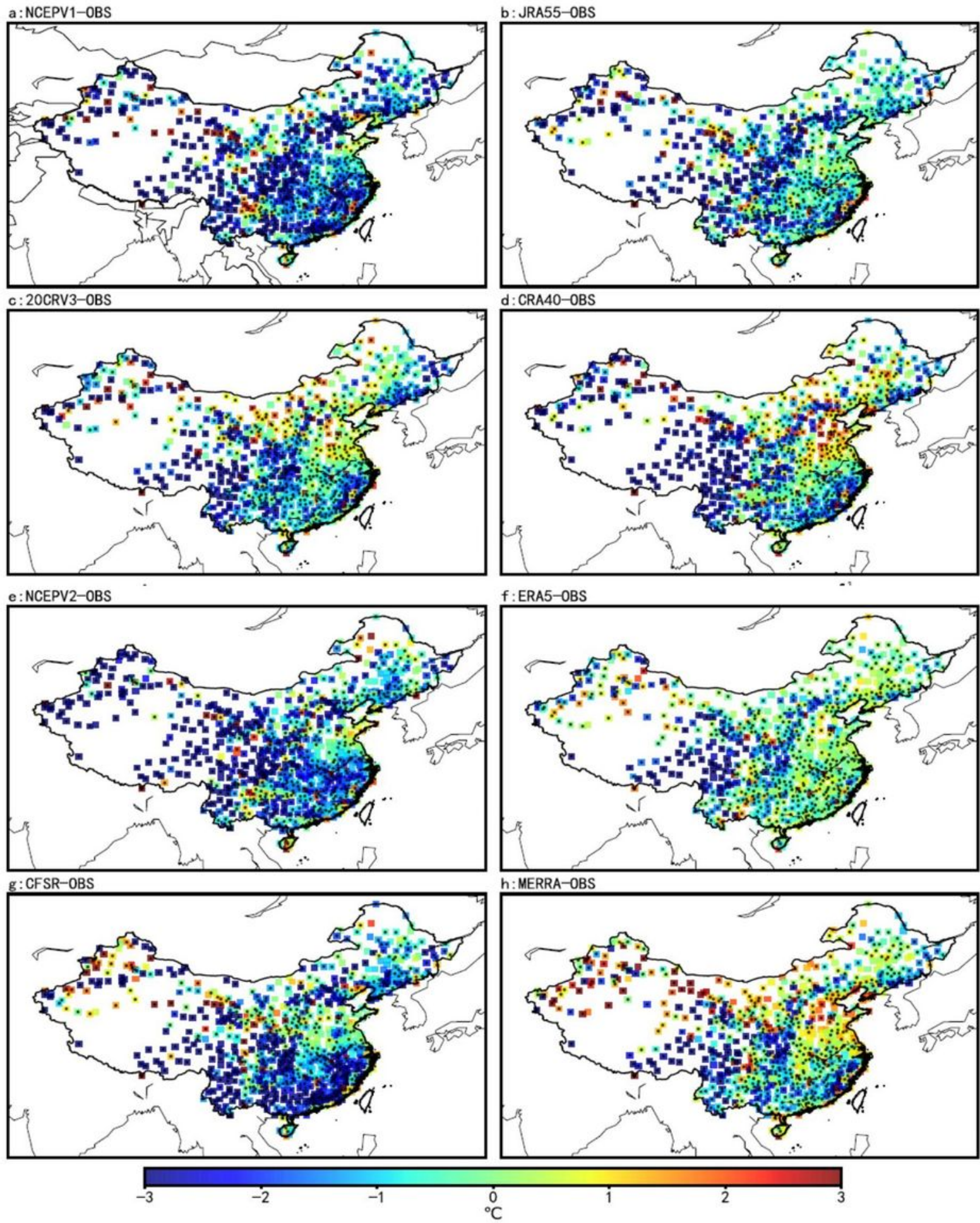

Figure 6

Spatial distribution of annual mean SAT bias of REAs from observations for the period 1979-2015 across mainland China: (a) NCEPV1; (b) JRA55; (c) 20CRV3; (d) CRA40; (e) NCEPV2; (f) ERA5; (g) CFSR; (h) MERRA. (The black dots represent significant deviation, the value of color bar means the annual mean SAT bias (units: $\left.{ }^{\circ} \mathrm{C}\right)$ ) Note: The designations employed and the presentation of the material on this map do not imply the expression of any opinion whatsoever on the part of Research Square concerning the 
legal status of any country, territory, city or area or of its authorities, or concerning the delimitation of its frontiers or boundaries. This map has been provided by the authors.
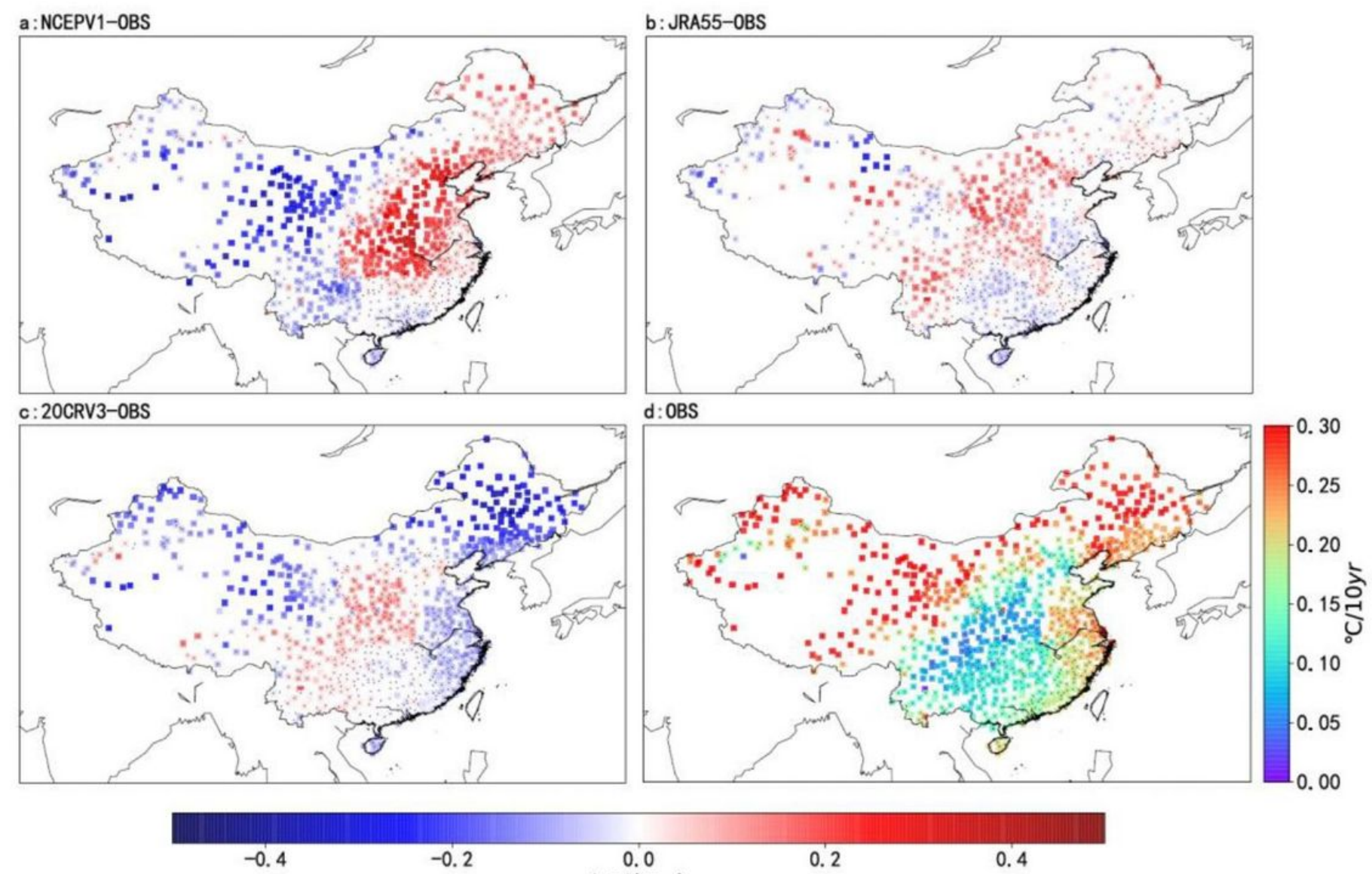

$-0.2$

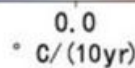

0.2

0.4

\section{Figure 7}

Spatial distribution of linear trend of OBS and linear trend bias between REA and OBS for the period 1961-2015 across China:(a) NCEPV1; (b) JRA55; (c) 20CRV3 (d) OBS. (The black dots represent significant deviation, the value of color bar means the linear trend bias and linear trend (units: ${ }^{\circ} \mathrm{C} / 10$ year)) Note: The designations employed and the presentation of the material on this map do not imply the expression of any opinion whatsoever on the part of Research Square concerning the legal status of any country, territory, city or area or of its authorities, or concerning the delimitation of its frontiers or boundaries. This map has been provided by the authors. 

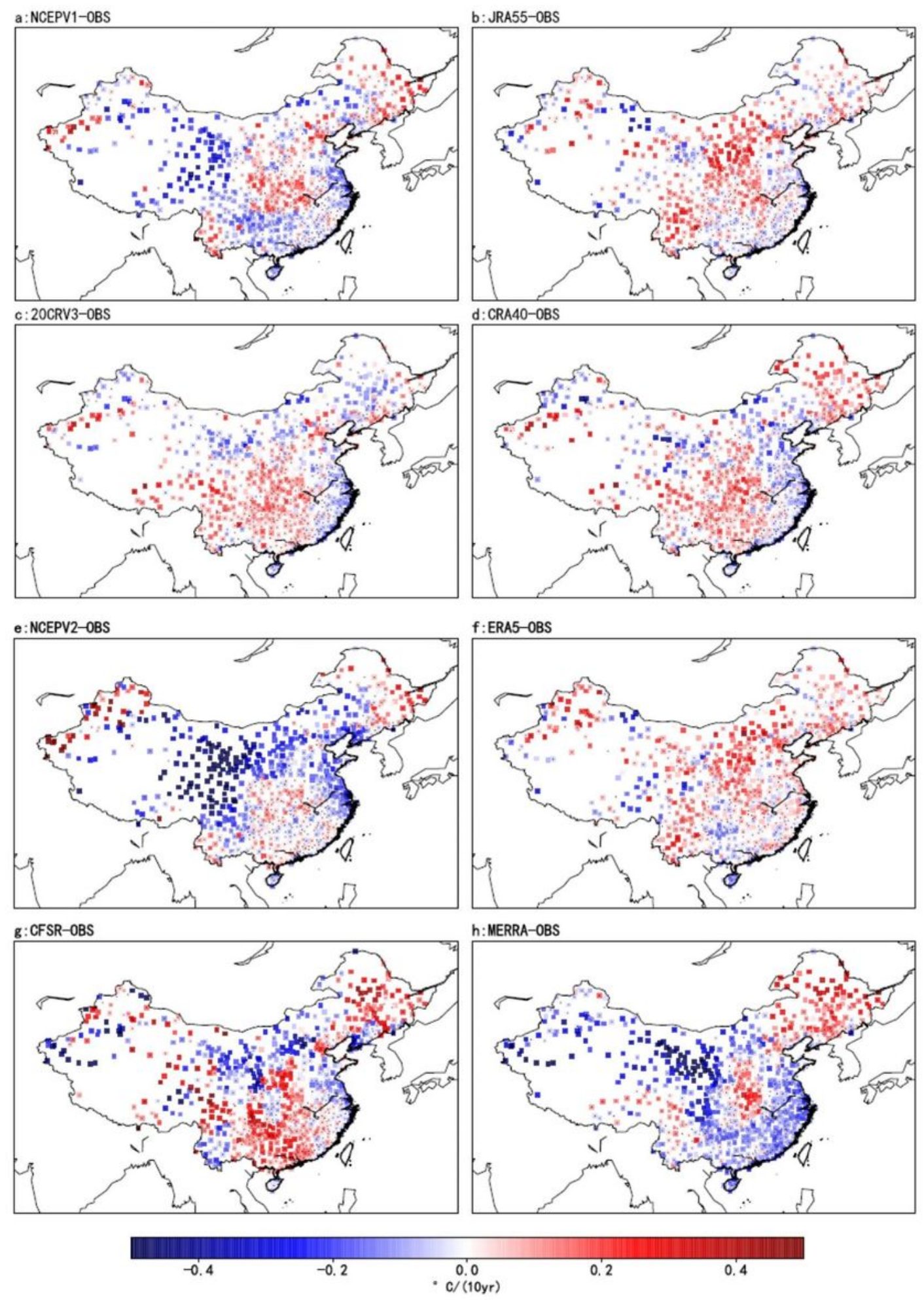

\section{Figure 8}

Spatial distribution of linear trend bias between REA and OBS for the period 1979-2015 across China:(a) NCEPV1; (b) JRA55; (c) 20CRV3; (d) CRA40; (e) NCEPV2; (f) ERA5; (g) CFSR; (h) MERRA. (The black dots represent significant deviation, the value of color bar means the linear trend bias (units: $\left.{ }^{\circ} \mathrm{C} / 10 y e a r\right)$ ) Note: The designations employed and the presentation of the material on this map do not imply the expression of any opinion whatsoever on the part of Research Square concerning the legal status of any country, 
territory, city or area or of its authorities, or concerning the delimitation of its frontiers or boundaries. This map has been provided by the authors.
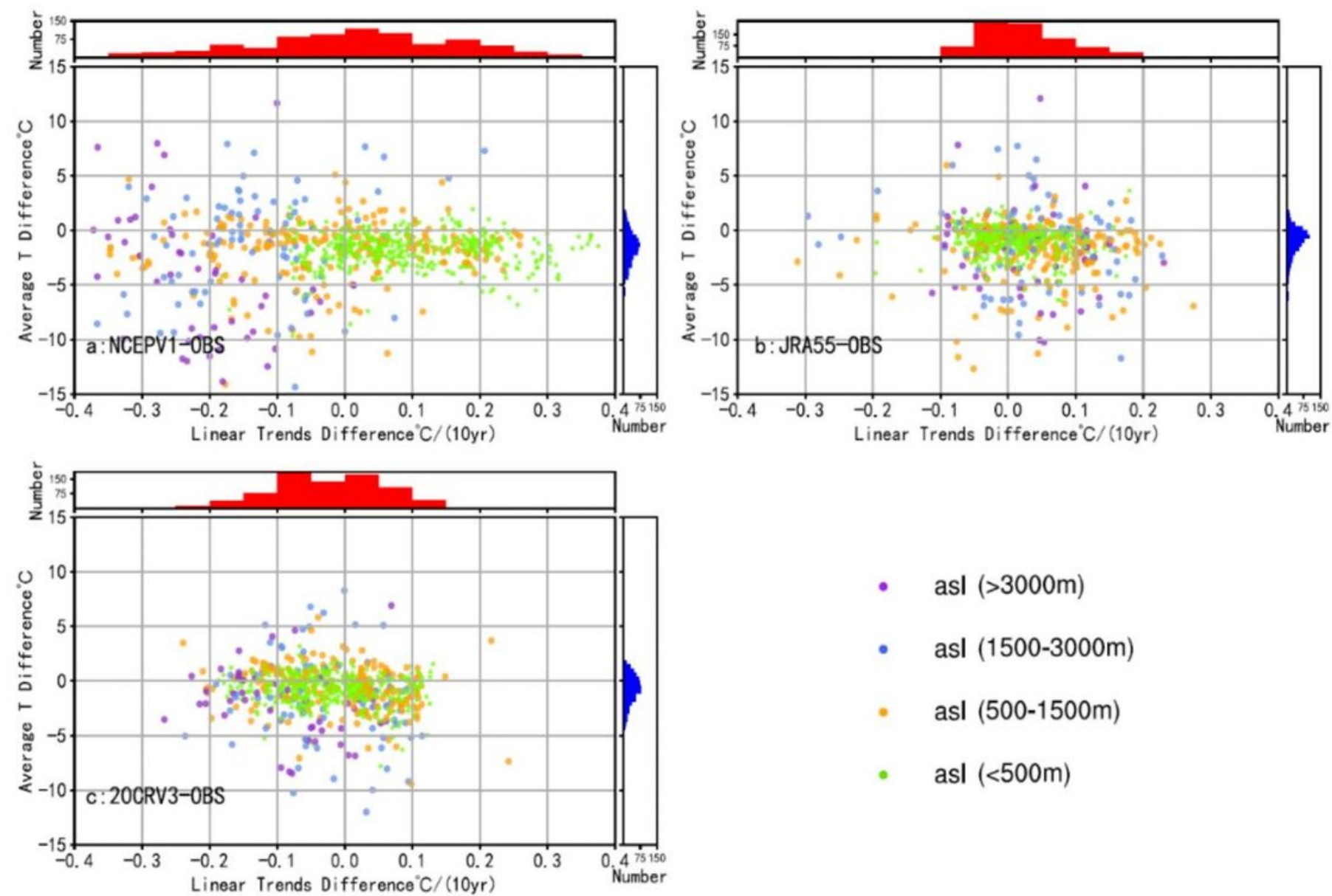

- $\quad$ asl $(>3000 \mathrm{~m})$

- asl (1500-3000m)

asl $(500-1500 \mathrm{~m})$

asl $(<500 \mathrm{~m})$

\section{Figure 9}

The biases of climate state and linear trends of annual mean temperature between REAs and OBS for the period 1961-2015. (a) NCEPV1; (b) JRA55; (c) 20CRV3. (The asl stands for elevation (units: m); $y$-axis stand for the bias of climate state (units: ${ }^{\circ} \mathrm{C}$ ); $\mathrm{x}$-axis stand for the bias of linear trends (units: ${ }^{\circ} \mathrm{C} / 10$ years); red bar stand for the number of stations with different bias of linear trends; blue bar stand for the number of stations with different bias of climate state; purple dots represent the altitude of stations above $3000 \mathrm{~m}$;blue dots represent the altitude of stations between $1500-3000 \mathrm{~m}$; orange dots represent the altitude of stations between $500-1500 \mathrm{~m}$; green dots represent the altitude of stations less than $500 \mathrm{~m}$ ) 

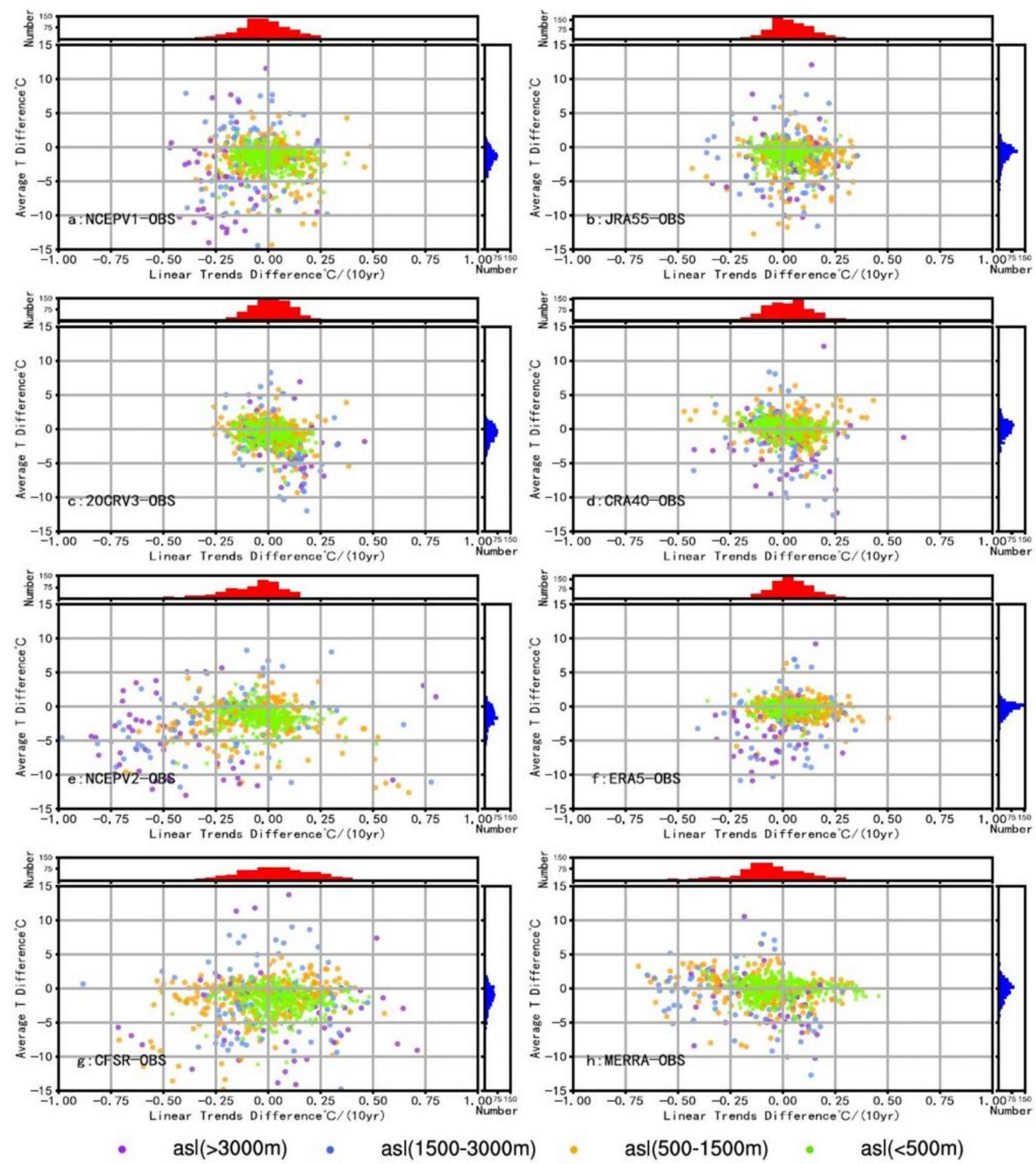

$\operatorname{asl}(500-1500 m) \quad \therefore \quad \operatorname{asl}(<500 m)$

\section{Figure 10}

The biases of climate state and linear trends of annual mean temperature between the REAs and OBS for the period 1979-2015. (a) NCEPV1; (b) JRA55; (c) 20CRV3; (d) CRA40; (e) NCEPV2; (f) ERA5; (g) CFSR; (h) MERRA. (The asl stands for elevation (units: $\mathrm{m}$ ); $\mathrm{y}$-axis stand for the bias of climate state (units: ${ }^{\circ} \mathrm{C}$ ); $\mathrm{x}$ axis stand for the bias of linear trends (units: ${ }^{\circ} \mathrm{C} / 10$ years); red bar stand for the number of stations with different bias of linear trends; blue bar stand for the number of stations with different bias of climate 
state; purple dots represent the altitude of stations above $3000 \mathrm{~m}$;blue dots represent the altitude of stations between $1500-3000 \mathrm{~m}$; orange dots represent the altitude of stations between $500-1500 \mathrm{~m}$; green dots represent the altitude of stations less than $500 \mathrm{~m}$ )

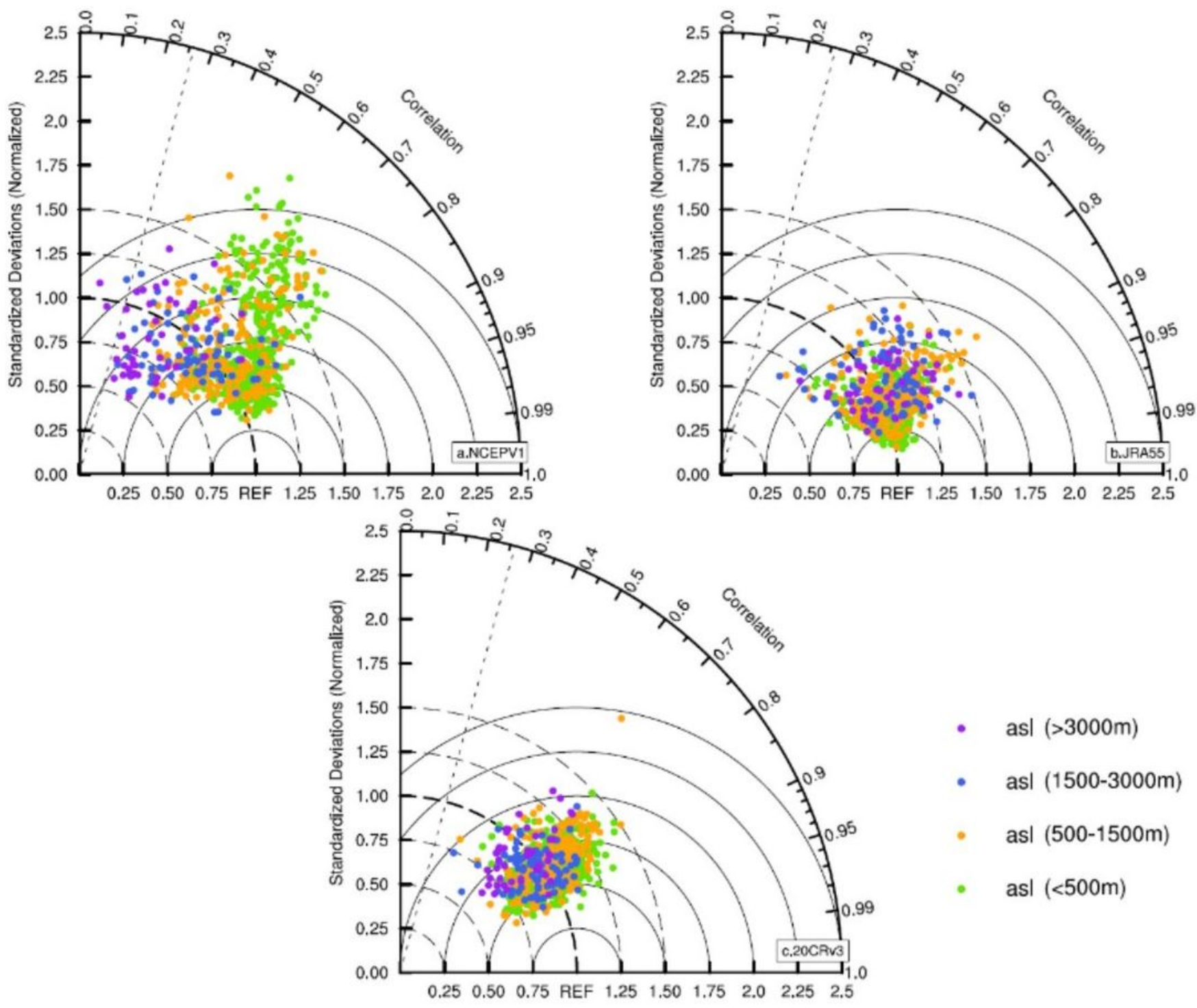

\section{Figure 11}

Taylor diagrams of annual mean SAT for 763 stations across mainland China derived by the REAs and OBS for the period 1961-2015: (a) NCEPV1; (b) JRA55; (c) 20CRV3. (The asl stands for elevation (units: $\mathrm{m}$ ), the purple dots represent the altitude of stations above $3000 \mathrm{~m}$. The blue dots represent the altitude of stations between $1500-3000 \mathrm{~m}$. The orange dots represent the altitude of stations between $500-1500 \mathrm{~m}$. The green dots represent the altitude of stations less than $500 \mathrm{~m}$, threshold for the $95 \%$ confidence level is 0.26) 

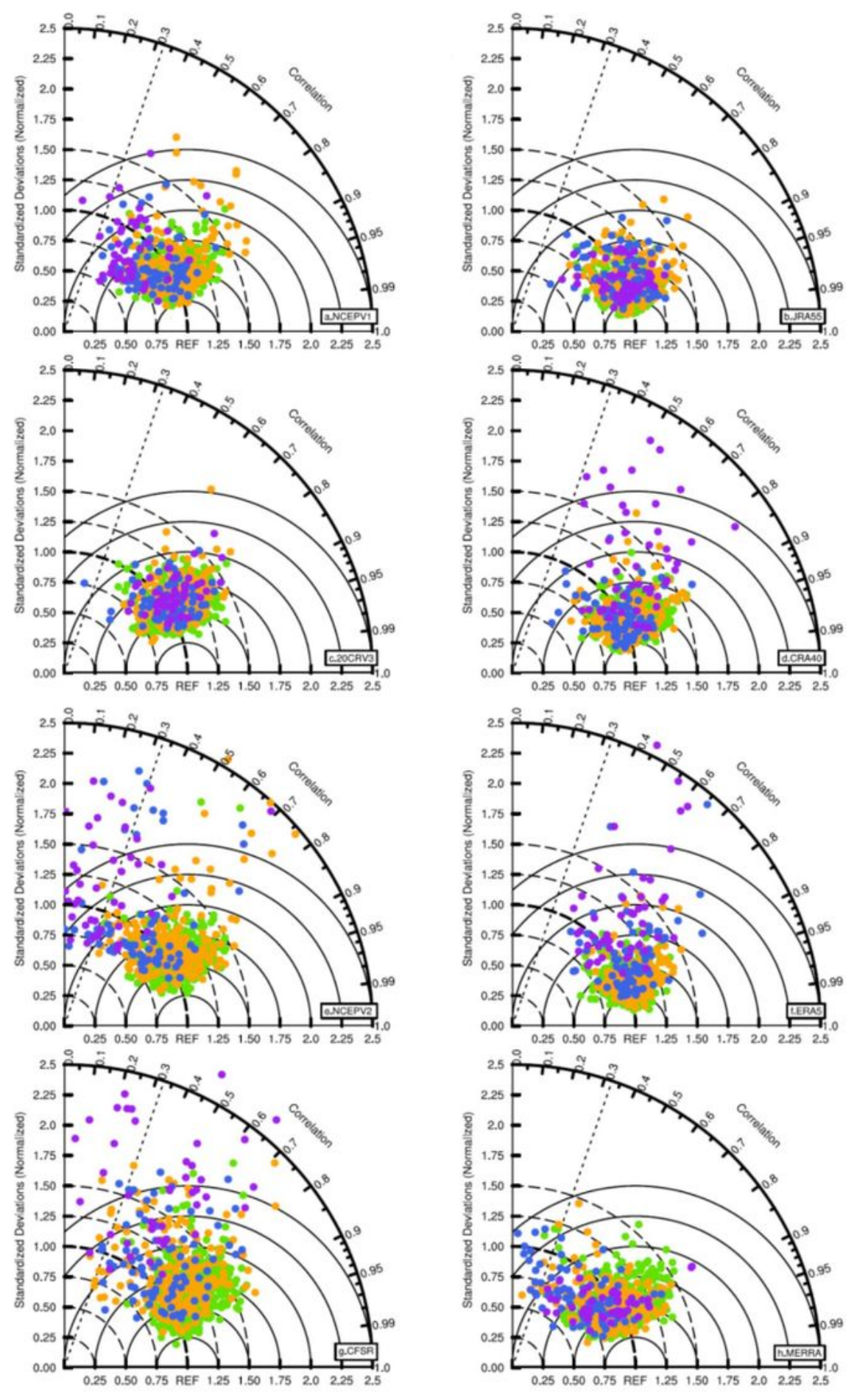

- $\quad$ asl $(>3000 \mathrm{~m})$ - asl $(1500-3000 \mathrm{~m})$

asl $(500-1500 \mathrm{~m}) \quad$ asl $(<500 \mathrm{~m})$

\section{Figure 12}

Taylor diagrams of annual mean SAT for 763 stations across mainland China derived by the REAs and OBS for the period 1979-2015:(a) NCEPV1; (b) JRA55; (c) 20CRV3; (d) CRA40; (e) NCEPV2; (f) ERA5; (g) CFSR; (h) MERRA. (The asl stands for elevation (units: $\mathrm{m}$ ), the purple dots represent the altitude of stations above $3000 \mathrm{~m}$. The blue dots represent the altitude of stations between $1500-3000 \mathrm{~m}$. The orange 
dots represent the altitude of stations between $500-1500 \mathrm{~m}$. The green dots represent the altitude of stations less than $500 \mathrm{~m}$, threshold for the $95 \%$ confidence level is 0.32 ) 